\title{
Forecasting the educational structure of occupations : a manpower requirement approach with substitution
}

Citation for published version (APA):

Borghans, L., \& Heijke, J. A. M. (1993). Forecasting the educational structure of occupations : a manpower requirement approach with substitution. Researchcentrum voor Onderwijs en Arbeidsmarkt, Faculteit der Economische Wetenschappen. ROA Research Memoranda No. 2E https://doi.org/10.26481/umaror.199302E

Document status and date:

Published: 01/01/1993

DOI:

10.26481/umaror.199302E

Document Version:

Publisher's PDF, also known as Version of record

\section{Please check the document version of this publication:}

- A submitted manuscript is the version of the article upon submission and before peer-review. There can be important differences between the submitted version and the official published version of record. People interested in the research are advised to contact the author for the final version of the publication, or visit the DOI to the publisher's website.

- The final author version and the galley proof are versions of the publication after peer review.

- The final published version features the final layout of the paper including the volume, issue and page numbers.

Link to publication

\footnotetext{
General rights rights.

- You may freely distribute the URL identifying the publication in the public portal. please follow below link for the End User Agreement:

www.umlib.nl/taverne-license

Take down policy

If you believe that this document breaches copyright please contact us at:

repository@maastrichtuniversity.nl

providing details and we will investigate your claim.
}

Copyright and moral rights for the publications made accessible in the public portal are retained by the authors and/or other copyright owners and it is a condition of accessing publications that users recognise and abide by the legal requirements associated with these

- Users may download and print one copy of any publication from the public portal for the purpose of private study or research.

- You may not further distribute the material or use it for any profit-making activity or commercial gain

If the publication is distributed under the terms of Article $25 \mathrm{fa}$ of the Dutch Copyright Act, indicated by the "Taverne" license above, 
FORECASTING THE EDUCATIONAL STRUCTURE OF OCCUPATIONS: A MANPOWER REQUIREMENT APPROACH WITH SUBSTITUTION

ROA-RM-1993/2E

Lex Borghans and Hans Heijke

Faculty of Economics and Business Administration University of Limburg

Maastricht, December 1993 


\section{CIP GEGEVENS KONINKLIJKE BIBLIOTHEEK, DEN HAAG}

Borghans, Lex

Forecasting the educational structure of occupation : a manpower requirement approach with substitution/Lex Borghans and Hans Heijke. - Maastricht: Research Centre for Education and the Labour Market, Faculty of Economics and Business Administration, Rijksuniversiteit Limburg. (ROA-RM-1993/2E)

Met lit. opg.

ISBN 90-5321-135-7

Trefw.: arbeidsmarktprognoses/onderwijs en arbeidsmarkt. 


\section{CONTENTS}

Page

1. INTRODUCTION

2. THE DATA 5

3. MEASUREMENT OF FORECAST ERRORS

4. THE MANPOWER REQUIREMENT APPROACH 11

5. INTERPRETING THE GAP BETWEEN REQUIREMENT AND SUPPLY 17

6. RAS 21

\begin{tabular}{ll}
7. & SUBSTITUTION \\
\hline
\end{tabular}

8. CALCULATING $g_{i}^{s}$ AND $\alpha_{i j}$

9. FORECASTING 29

10. EXTENSIONS OF THE MANPOWER FORECAST MODEL

11. CONCLLUSIONS 37

$\begin{array}{ll}\text { REFERENCES } & 38\end{array}$

APPENDIX 1. OCCUPATIONS WITH THEIR OCCUPATIONAL LEVEL IN 1985

APPENDIX 2. TYPES OF EDUCATION WITH THEIR INSTITUTIONAL LEVEL 41

APPENDIX 3. THE INCORPORATION OF UNEMPLOYMENT IN THE MANPOWER
MODEL (7.9)-(7.13) 


\section{INTRODUCTION}

Since education is generally seen as an important factor for the economic performance of a country, the development of the educational structure of the labour force is often regarded by governments as a matter of great concern. Therefore, besides forecasts of economic developments forecasts of the educational structure are regarded as important. Blaug (1972, p. 137) remarks that 'educational planning by the State with the purpose of promoting economic objectives is now as universally approved as economic planning itself'. He continues that 'the concept of "forecasting manpower requirements" is today the leading method throughout the world for integrating educational and economic planning' (p. 137).

Educational forecasts may have two different types of objectives. ${ }^{1}$ Firstly, it might be important for the government to have insight in the expected changes in the field of education. Since the government often is an important investor in the educational system, relevant information about these changes might enable her to adjust these investments in time. Usually, forecasts are furthermore regarded as relevant for government because, in case of expected shortages or surpluses, it enables a policy which adjusts these discrepancies between supply and demand. In a free market economy, however, it is not in the first place the government which regulates the investment decisions in human capital, but the students themselves are to a large extent - free to make an educational choice.

In the manpower requirement approach typically forecasts are made of the future labour market situation of types of education, in which demand and supply are forecasted independently. The basic assumption of this approach is that the demand (or requirement) for labour of a certain type of education can be recognised as such in a sensible way. Both forecasts - requirements and supply - are compared and if the supply does not match the requirements, labour market problems are predicted. This comparison leads to a surplus or to a shortage, and these are, in the pure requirement approach, regarded as discrepancies which have to be bridged by an adequate policy, because in case of a surplus educational resources are inefficiently used and in case of a shortage economic goals cannot be attained. In case of an adequate policy these gaps - in case they were predicted - will therefore not be observed afterwards.

Secondly, if, as in a free market system, the government has no significant role in the educational decisions of students, the forecasts of the educational structure of the future labour market might, nevertheless, be important. The forecasts can be used as public information which is relevant for students. Borghans (1993) shows that the provision of labour market forecasts to students may improve their educational choice, and therefore reduce the mismatch between supply and demand. In such a situation it is not guaranteed anymore that students' choices will automatically adjust to information about a gap between supply and demand such that the expected gap will disappear. In this market based framework students will not change their behaviour because of the existence of a gap between supply and demand, but discrepancies at the market will affect the market position of different types of education (e.g. changes in the wages, or in the level of unemployment). These changes in the market position, might, if correctly anticipated, change students' behaviour. In a more pragmatic view the gaps, predicted by the manpower requirement approach, are therefore regarded as indicators for the labour market position of the types of education, rather than as directly observable phenomena. In the free market framework, furthermore, it might be questioned what is the meaning of a requirement. In a free market the optimal situation, i.e. a situation without mismatch, ${ }^{2}$ is a

1. Soumelis (1983, pp. 34-35).

2. See Borghans (1993, chapter 2). 
situation in which supply, represented by the preferences and capabilities of the students, and demand, represented by the production possibilities of employers, are optimally adjusted. The target in a free market context therefore is not a demand side production target, but is implicitly constructed by both supply and demand side characteristics.

From this free market point of view the approach of predicting surpluses and shortages for educational types in the usual manpower requirement approach has several, closely connected, shortcomings. Firstly, the prediction of a surplus or shortage is, as remarked above, an abstract theoretical construct. In actual practice a shortage as such will not be noticed. Surpluses are possibly observed by increasing unemployment, lower wages, or people changing to lower level jobs. Shortages might manifest themselves in difficulties to fill vacancies, higher wages, or the hiring of people for certain jobs with a less appropriate education. The prediction of a surplus or shortage, provides, however, no information about the effects of such a situation at the labour market.

A second shortcoming of the requirement approach is that it does not take into account the fact that surpluses or shortages for one type of education influence the labour market situation of other types. For some types of education (e.g. higher education) surpluses do, mainly, not lead to unemployment, but result in bumping down processes. The higher educated get jobs at a lower level and therefore the demand for people at the intermediate level decreases. The usual independent projections of supply and demand do not take into account these substitution effects.

A third disadvantage of the surplus/shortage forecasts is that, due to the hypothetical character, it is not possible to make straightforward evaluations of the forecasts. The model only predicts the hypothetical gap between supply and demand, which can not be measured directly. Measurement requires additional forecasts about what will happen with the shortage or the surplus. They provide no direct information about the requirements itself.

A conceptual problem which arises in this approach is that the observed educational structure of occupations reflects the substitution processes which took place. These figures are used, however, to forecast requirement rather than demand ('before' substitution takes place).

One reason not to forecast the interdependency between supply and demand is usually said to be the lack of wage-figures. Freeman (1980), however, shows that the availability of data on wages is not necessary for the estimation of elasticities of demand. The aim of this paper is to make forecasts about the educational structure of occupations which does take into account the substitution process, without the use of wage-figures. Wages are treated as latent variables. The reason to treat wages only as latent variables, of course, is that wage-figures are not available, but besides that, there is another reason not to expect too much from the use of data on wages. This reason is that in the process of market clearing supply and demand for certain jobs are not only influenced by wages, but many other aspects of the job also play a role, and determine together the attractiveness of the job. In reality the labour market is much more complex than in text books. Instead of wages it may be better to speak about marketpower or the labour market position of a type of education. The advantage of not having explicit the wages in a model is that it allows for many interpretations of the latent wages.

in the manpower forecasting literature the only model which really models the interaction 
between supply and demand instead of two separate developments is the RAS-model ${ }^{3}$. The model developed in this paper is an alternative to RAS, which has some interesting properties compared to it. From a certain point of view the substitution model in this paper can be regardes as a linear approximation to RAS. This way of modelling the substitution proces has, however, some advantages. Firstly, the model is more flexible, allowing for extensions based on economic theory. Secondly, although it takes into account the interaction effects between different markets the model is formulated in such a way that it still fits into the requirement approach, since it measures the gap between supply and the requirement. An aim of this paper is to show that even in a free market context it is still possible to interpret requirements, and that with some necessary adjustments the manpower requirement model can be used for forecasting in this context.

Furthermore, the model provides predictions about the distribution of a type of education over the occupations. These forecasts can, contrary to the requirements, be evaluated directly and may be used for other indicators, e.g. the future average job-level, or the future job-dispersion.

In this paper the forecast quality of the manpower requirement model with substitution is compared with alternative approaches and three types of extensions of the basic model are presented in which the changes on the labour market are predicted using job and educational level as explanatory variables. All these models are estimated with data taken from the Dutch labour force census. The manpower requirement model with substitution, which is rather simular to RAS, has also a forecast quality comparable to RAS. Both models, RAS and MPS, appear to be much better than other approaches to forecast the future employment by education models with substitution. The possibility to introduce economic extensions, explaning the changes in demand and the substitution processes at the labour market by occupational and educational characteristics, brings the possibilities of the manpower model of this paper beyond the RAS-model. In the paper three different types of extensions are estimated which relate respectively initial requirement, the elasticity of demand, and substitution to the educational and occupational level. Although these extensions provide forecasts of the educational structure of occupations which are only slightly better than the basic model, these extensions seem to be important for plausible forecasts of the gap between requirement and supply. For an appropriate description of labour market processes such extensions seem to be very useful.

The forecasts in this paper are made within the framework of a larger forecasting project, carried out by the Research Centre for Education and the Labour Market (ROA) (see for this project: Heijke (ed.), 1994, chapters 3, 6 and 9). For that reason some aspects of the future labour market, forecasted by other parts of this project, are treated as given. These inputs are the supply per type of education, and the demand for labour per occupation. The model of this paper therefore has to predict the educational structure of occupations given total supply per education and total demand per occupation.

The paper is organised as follows. In section 2 a description of the data which are used to make the manpower forecasts is given. Furthermore, in order to be able to compare different forecast models a criterium has to be introduced which measures the quality of a forecast. This is done in section 3, and since sample errors are an important aspect of both forecasting and evaluation errors, special attention is paid to this kind of error.

3. E.g. Evans and Lindley (1973), Bosworth, Evans, and Lindley (1974), and Van Eijs and Borghans (1993). 
In section 4 the essential characteristics of the manpower requirement approach are provided. It will be shown that a usual way to implement this approach leads to very disappointing forecasting results. The shortcomings of these implementations are however not fundamental to the manpower requirement approach. As will be shown in section 5 it is possible to interpret the manpower requirement approach, which is based on 'the gap between supply and demand', in a theoretically satisfactory way. A forecasting model which can be interpreted as an example of such a theoretically satisfactory manpower forecasting model in the RAS-model. This model is explained in section 6, in which also some of the shortcomings of the RAS-model are exposed. In section 7 an alternative model is presented which overcomes these shortcomings. In its basic form it is very similar to the RAS-model, but its specification is much more flexible and within this manpower model with substitution (MPS) it is possible to implement the 'gap between supply and demand' as a very useful indicator of the expected labour market position of types of education.

Section 8 presents two ways to calculate reasonable values for the parameters of the MPS model. In section 9 the forecasting results of these methods are compared indicating that the most flexible way to calculate the parameters is inferior to the more rigid alternative. Most likely random influences and errors in the labour force survey disturb the parameter estimates of the flexible method to much.

Based on the more rigid model, with a better forecasting quality, in section 10 at three essential points extensions of the basic MPS model, are developed. These examples indicate the possible ways in which future developments of this Manpower Model with Substitution might go. Finally, in section 11 , some conclusions are drawn. 


\section{THE DATA}

The analyses in this paper have been performed with data of the Dutch labour force censuses (AKT) of 1979, 1981, 1983, and 1985. For each year they provide information about the number of people working with a certain educational background in a certain occupation. The classification of the occupations and the educations is according to the ROA-classifications. ${ }^{4}$ By this classification occupations have been clustered in such a way that those with a similar educational structure are in one group. There are 54 types of education and 49 occupational classes. Appendix 1 provides a list of jobs, and appendix 2 of the types of education. The analyses abstracts from unemployed, what is an important shortcoming. The labour force censuses being sample data provide, however, no useful information about unemployment at the rather low aggregation level used in this paper. Appendix 3 pays attention to the way unemployment can be incorporated in the forecasting model developed in this paper.

$a_{i j}^{\ell}$ denotes the number of people working in occupation $j$ with education $i$. In this paper $i$ will always be used as index for the type of education and $j$ as index for the occupations. All $a_{i j}$ together form the matrix $A^{t}$.

Based on these data, forecasts will be made of the future educational structure of occupations. To make possible an evaluation of these forecasts, always one of the four labour force censuses is used as the year which has to be forecasted. The educational structure recorded in this year is therefore not used to make the forecast. The total number of people working per education or per occupation, i.e. the total demand per occupation $d_{j}^{t}=\sum_{i} a_{i j}^{t}$ and the workforce per type of education supply the $s_{i}^{t}=\sum_{j} a_{i j}^{t}$ are, however, assumed to be known. In the actual forecasting practice these figures should be replaced by forecasts of supply per type of education and demand per type of occupation. These forecasts are investigated in other papers that are composed within the framework of the ROA labour market forecasting project. ${ }^{5}$ This assumption that supply and demand are known makes it possible to separate forecasts errors of these other models from errors in the model which predicts the educational structure developed in this paper.

Furthermore, in the models developed in this paper job-level and educational level will be used as explanatory variables. The educational level is determined by the official status of the education. Academic education is labelled 5, higher vocational education 4, intermediate vocational education together with higher general secondary education and pre-university education 3, while lower vocational education and lower general secondary education are labelled 2. People with only primary education get label 1 .

The job-level has been calculated by use of the matrix type of education by occupation of a certain year. The job-level equals the average educational level, weighted with the amount of people with a certain education in this job. Therefore, the job-level indicates the average educational level of its workers. Thus, if $l_{i}$ denotes the institutional educational level then the job level of occupation $j$ in year $t$ is defined as:

4. See Dekker, De Grip, and Van de Loo (1990), and Dekker and De Grip (1992) for the occupational classification which originates from De Grip, Groot and Heijke (1991), and Dekker et al. (1992) for the method in general.

5. Dekker et al. (1992), Berendsen et al. (1992) and Willems and De Grip (1993). 
(2.1) $l_{j}^{t}=\frac{\sum_{i} a_{i j}^{t} l_{i}}{\sum_{i} a_{i j}^{t}}$

Appendix 1 and 2 provide the educational levels and the occupational levels in 1985. 


\section{MEASUREMENT OF FORECAST ERRORS}

The aim of this paper is to make a forecast of the educational structure of occupations in a certain year. The matrix education $\times$ occupation contains $54 \times 49=2646$ elements. Although many of them equal zero, aggregation is needed to evaluate the forecast quality. In this paper the following criterium is used:

(3.1) $Q\left(\hat{A}^{t}\right)=\sum_{i} \sum_{j: a_{i j}^{t}>0} \frac{\left(\hat{a}_{i j}^{t}-a_{i j}^{t}\right)^{2}}{a_{i j}^{t}}$

In which $\hat{A}^{t}$ is a prediction of $A^{t}$. There are two reasons for this choice of this criterium. Firstly, the aim of the manpower forecasts investigated in this paper is to inform students about the future labour market position of educations, to assist their educational choice. For one individual student not the total demand but only the relative change in the demand is relevant. Using a quadratic loss-function this equals $\left(\left(\hat{a}_{i j}^{t}-a_{i j}^{t}\right) / a_{i j}^{t}\right)^{2}$. Summation over all students, and assuming that students will be distributed over the labour market proportionally to the total of workers, the criterium becomes equal to (3.1), since

$\sum\left(\frac{\left(\hat{a}_{i j}^{t}-a_{i j}^{t}\right)}{a_{i j}^{t}}\right)^{2} \cdot a_{i j}^{t}=\sum \frac{\left(\hat{a}_{i j}-a_{i j}^{t}\right)^{2}}{a_{i j}^{t}}$

Secondly, there is a technical reason to take criterium (3.1). To optimise the forecast method the assumption is made that the forecast errors are randomly distributed. The distribution of the error term must be independent of $a_{i j}^{t}$. Table 3.1 gives the results of three estimations in which the squared error is explained by a constant, $a_{i j}$, and $a_{i j}^{2}$. In the first column the forecast for 1985 has been made by simply taking the matrix $A$ of 1983 (this 'forecast' will be called Same As Before, SAB). In column 2 and 3 the squared forecasts errors are used from two standard forecast methods which will be explained later, MPS and RAS. The table shows that for SAB the best explanation of the squared forecast error is the quadratic error term. For the two real forecast methods, however, the optimal explanation uses $a_{i j}$ instead of the quadratic term. This indicates that changes in the matrix $A$ are proportional to $a_{i j}$, but that the forecast errors of real forecasts are proportional to $\sqrt{a_{i j}}$ (i.e. the quadratic forecast error is proportional to $a_{i j}^{2}$ ), what suggest the appropriateness of (3.1).

Table 3.1. An explanation of the quadratic forecast errors (t-values between brackets)

\begin{tabular}{|c|c|c|c|}
\hline & $S A B$ & MPS & RAS \\
\hline constant & $\begin{aligned} 267 & 10^{3} \\
(0.53) & \end{aligned}$ & $\begin{aligned} 34 & 10^{3} \\
(0.09) & \end{aligned}$ & $\begin{array}{r}61 \\
(0.16)\end{array}$ \\
\hline$a_{i j}$ & $\begin{array}{r}287 \\
(3.92)\end{array}$ & $\begin{array}{r}327 \\
(6.07)\end{array}$ & $\begin{array}{r}309 \\
(5.66)\end{array}$ \\
\hline$a_{i j}^{2}$ & $\begin{array}{r}9.7210^{-3} \\
(18.93)\end{array}$ & $\begin{array}{c}-0.82810^{-3} \\
(2.19)\end{array}$ & $\begin{array}{c}-0.02410^{-3} \\
(0.63)\end{array}$ \\
\hline
\end{tabular}

The use of this criterium also leads to the most stable estimation results. The same criterium is used by Bosworth, Evans, and Lindley (1974) and Evans and Lindley (1973). Table 3.2 shows, 
however, that the choice of the criterium matters. Again the forecast quality of the three estimation methods is presented, with four different quality criteria. MPS is the best for all criteria except for the second in which SAB is better. In general it can be said that many results in this paper depend on the choice of the forecast quality criterium.

Table 3.2. The quality of different forecasts using four different criteria (for 1985)

$$
\sum\left|\hat{a}_{i j}-a_{i j}\right| \quad \sum\left(\frac{\hat{a}_{i j}-a_{i j}}{a_{i j}}\right)^{2} \quad \sum \frac{\left(\hat{a}_{i j}-a_{i j}\right)^{2}}{a_{i j}}(0) \quad \sum\left(\hat{a}_{i j}-a_{i j}\right)^{2}
$$

\begin{tabular}{|c|c|c|c|c|}
\hline$S A B$ & $82310^{3}$ & 1,938 & $39710^{3}$ & $4,46410^{6}$ \\
\hline RAS & $61010^{3}$ & 2,245 & $31510^{3}$ & $1,60210^{6}$ \\
\hline MPS & $58910^{3}$ & 2,146 & $30310^{3}$ & $1,49710^{6}$ \\
\hline
\end{tabular}

The forecast errors are of course caused by unexpected (or unexplained) changes in demand and supply on the labour market. Partly, however, they are also caused by measurement errors in the labour market censuses. To get an impression of these errors two calculations have been made: a theoretical and an empirical estimation of the measurement error.

The data in each cell of the matrix $A$ can be viewed on as based on a draw from the binomial distribution $B\left(n, p_{i j}\right)$, in which $p_{i j}$ represents the probability that a person has education $i$ and occupation $j$. The number of draws $n$ equals the sampled fraction times the total labour force: $n=\theta L$. Furthermore, $a_{i j}=\frac{n p_{i j}}{\theta}$. Therefore

$$
\operatorname{VAR}\left\{a_{i j}\right\}=\frac{n p_{i j}\left(1-p_{i j}\right)}{\theta^{2}}=\frac{\operatorname{Lp} p_{i j}\left(1-p_{i j}\right)}{\theta}
$$

Assuming the errors of each cell to be independent, the variance of the measurement error according to (3.1) becomes:

$$
\operatorname{VAR}\{Q(A)\}=\sum_{i j: a_{i j}>0} \frac{L p_{i j}\left(1-p_{i j}\right)}{\theta p_{i j} L}=\sum_{i j: a_{i j}>0} \frac{1-p_{i j}}{\theta}=\frac{\#(A)-1}{\theta}
$$

$\#(A)$ represents the number of non-zero elements in $A$.

Table 3.3. The measurement error according to (3.3)

\begin{tabular}{lllllll}
\hline & sample size & $\begin{array}{l}\text { non- } \\
\text { response }\end{array}$ & $\theta$ & $\theta$ CBS & $\#(\mathrm{~A})$ & $Q\left(a_{i j}\right)$ \\
\hline 1979 & $2.5 \%$ & $18.7 \%$ & 0.02033 & 0.02012 & 1396 & $6910^{3}$ \\
1981 & $5 \%$ & $17.3 \%$ & 0.04135 & 0.04065 & 1615 & $4010^{3}$ \\
1983 & $3 \%$ & $18.2 \%$ & 0.02454 & 0.02404 & 1528 & $6410^{3}$ \\
1985 & $3 \%$ & $22.1 \%$ & 0.02337 & 0.02273 & 1512 & $6610^{3}$ \\
\hline
\end{tabular}

Table 3.3 presents the estimated measurement errors in $Q$ for the four labour force censuses. Information about the sample size and the non-response is from CBS $11982,1985,1986$, 1987). These CBS publications also provides a calculation of $\theta$, which is lower than the sample ratio which can be calculated from the figures mentioned before. 
The measurement errors in table 3.3 are based upon the assumption that the sampling, the questioning, and the processing of the data have been performed perfectly. CBS $(1982,1985$, $1986,1987)$ warns, however, that there may be an additional error due to these factors. It is not possible to calculate the extent of this error on theoretical grounds. To get an impression of the additional error in the labour force censuses some forecast experiments have been performed. RAS and MPS both use the matrix $A$ in a base year to forecast the matrix in another year. The most obvious way to do this is to take the most recent year available. If the assumption is made that the educational structure in year $t$ can be described as the structure in year $t-1$ plus additional changes, it is possible to measure the measurement error for certain years. Suppose that a forecast of $a_{i j}^{t+2}$ based on $a_{i j}^{t+1}$ contains a real forecast error $E_{12}$ plus the measurements errors of year $t+1$ and $t+2\left(m_{1}\right.$ and $\left.m_{2}\right)$, etc. It then follows that:

(3.4) $Q(1-2)=E_{12}+m_{1}+m_{2}$

(3.5) $Q(0 \rightarrow 2)=E_{01}+E_{12}+m_{0}+m_{2}$

(3.6) $Q(0 \rightarrow 1)=E_{01}+m_{0}+m_{1}$

Assuming that the forecast errors $E$ are mutually independent, from these quality measures the measurement error in year 1 can be derived:

$$
m_{1}=\frac{Q(1+2)+Q(0-1)-Q(0-2)}{2}
$$

This method makes it possible to estimate the measurement errors for 1981 and 1983. Table 3.4 provides the results for these years based on both RAS and MPS.

Table 3.4. Estimations of measurement errors based on forecasts (RAS and MPS)

\begin{tabular}{llllll}
\hline year & method & $m_{t}$ & $\begin{array}{l}\text { theoretical } \\
\text { error } \\
\text { (see table 3.3) }\end{array}$ & $\begin{array}{l}\text { ratio with } \\
\text { theoretical } \\
\text { measure }\end{array}$ & $\begin{array}{l}\text { additional } \\
\text { error } \times \boldsymbol{\theta}\end{array}$ \\
\hline 1981 & RAS & $5110^{3}$ & $4010^{3}$ & 1.27 & 0.011 \\
1981 & MPS & $4810^{3}$ & $4010^{3}$ & 1.21 & 0.009 \\
1983 & RAS & $10310^{3}$ & $6410^{3}$ & 1.62 & 0.015 \\
1983 & MPS & $9710^{3}$ & $6410^{3}$ & 1.52 & 0.012 \\
\hline
\end{tabular}

The use of RAS and MPS leads to similar results, what indicates the robustness of the test. The third column provides the ratio between the estimated prediction error and the theoretical prediction error. For the relatively large sample of 1981 the additional prediction error equals on average $24 \%$, while for the small sample of 1983 this additional error equals on average $56 \%$. It might be expected that the additional measurement error is proportional to $1 / \theta^{2}$ and therefore relatively (compared to the theoretical measurement error) proportional to $1 / \theta$. If the extent of this error indeed decreases with the sample size, the third column suggests that with a sample of $1 \%$ the real forecast error will be twice as high as the theoretical error. This additional error halves if the sample size doubles. The results in table 3.4 should however be treated with care. The calculations are based upon the assumption that the forecasts errors in different years are not correlated. A violation of this assumption might distort the estimations.

Comparing these results about the reliability of the data with table 3.2 shows that the measurements errors forms a substantial part of the error of the forecasting models presented in that table. Recognizing that these errors will both affect the data on which the forecasts are 
based and the data which is used for evaluation purposes, implies that possibly $64 \%$ $(2 \times 97 / 303)$ of the error is caused by measurement error. Besides possible improvements of the manpower forecasting models themselves, which are the subject of this paper, it therefore seems very important to improve the quality of the data. This might be done by improvements of the survey - the sample fraction might be extended and the statistical treatment might become more precise - but also by filtering techniques which use information of past and 'future' years to improve the reliability of the employment data. 


\section{THE MANPOWER REQUIREMENT APPROACH}

As stated in the introduction of this paper in many countries frequently attempts are made to investigate the balance between supply and demand for certain occupational activities or types of education. The purpose of these studies - which often are restricted to specific types of occupations like teachers and health care occupations - is to regulate the inflow of students in order to avoid future shortages or surplusses. The usual approach to this research problem is the so-called manpower requirement approach (see Van Eijs, 1993 and 1994). The manpower requirement approach tries to forecast the need for labour with a certain educational background. Afterwards this need can be compared with the supply which might result in a gap - a shortage or a surplus - indicating discrepancies on the labour market. The fixed coefficient model $(F C)$ is a good example of the manpower requirement approach. Some forecasts differ from the fixed coefficient model, due to the fact that explanatory variables are used, while the fixed coefficient model does not. Conceptually, however, this difference does not matter.

In the fixed coefficient model the educational structure of each occupation is taken as constant. The future demand $\left(f c_{i j}^{t+1}\right)$ for type of education in an occupation is calculated by multiplying the observed amount of people with this type of education in this occupation $\left(a_{i j}^{t}\right)$ with the (predicted) growth-ratio of total demand in the occupation, which is assumed to be given (see section 1). The underlying assumption is that demand for a certain type of education increases proportionally with the total demand for an occupation.

$$
f c_{i j}^{t+1}=a_{i j}^{t} \frac{d_{j}^{t+1}}{d_{j}^{t}}
$$

Since the fixed coefficient model is based on the demand side forecasts:

(4.2) $\sum_{i} f c_{i j}^{t+1}=d_{j}^{t+1}$

Generally the same equality does not hold for supply $\left(s_{i}^{t+1}\right)$ :

(4.3) $\sum_{j} f c_{i j}^{t+1} \neq s_{i}^{t+1}$

$f c_{i j}^{t+1}$, therefore, can only be regarded as the requirement. The gap between supply and demand $g_{i}^{j c}$ is the shortage or surplus of this type of education:

(4.4) $g_{i}^{f_{c}}=\sum_{j} f c_{i j}^{t+1}-s_{i}^{t+1}$

This gap should indicate the expected labour market position of the types of education. The first column of table 4.1 gives these shortages and surpluses for the labour market in 1985, based on data of 1983. To make the figures more easy to interpret also a relative surplus or shortage has been provided, with $\bar{g}_{i}^{f c}=g_{i}^{f c} / s_{i}$. Shortages have a positive sign. 
Table 4.1. The gap between demand and supply in 1985 forecasted by the fixed coefficient model based on $1983^{*}$

\begin{tabular}{|c|c|c|}
\hline & gap & relative gap \\
\hline 1 Primary Education & 84,822 & 0.12 \\
\hline 2 Lower General Secondary Education & 42,950 & 0.11 \\
\hline 3 LVE, Agriculture & 3,346 & 0.03 \\
\hline 4 LVE, Technical & $-8,198$ & -0.02 \\
\hline 5 LVE, Transport \& Harbour & $-7,383$ & -0.23 \\
\hline 6 LVE, Commerce \& Administration & $-34,966$ & -0.24 \\
\hline 7 LVE, Community Care, Hotel \& Catering & 4,423 & 0.02 \\
\hline 8 LVE, Security & $-1,945$ & -0.35 \\
\hline 9 LVE, n.e.c. & $-7,923$ & -0.38 \\
\hline 10 Higher General Secondary Education & 707 & 0.00 \\
\hline $11 \mathrm{IVE}$, Agriculture & $-2,837$ & -0.03 \\
\hline 12 IVE, Non-Medical laboratory & -397 & -0.06 \\
\hline $13 \mathrm{IVE}$, Engineering & 13,505 & 0.02 \\
\hline 14 IVE, Transport \& Harbour & 525 & 0.01 \\
\hline 15 IVE, Medical Laboratory & $-1,436$ & -0.07 \\
\hline 16 IVE, Nursing \& Para-medical services & 1,596 & 0.01 \\
\hline 17 IVE, Commerce \& Administration & $-36,894$ & -0.07 \\
\hline 18 IVE, Administrative, legal \& Fiscal & $-2,060$ & -0.05 \\
\hline 19 IVE, Social \& Cultural & $-1,239$ & -0.05 \\
\hline 20 IVE, Community Care & $-1,217$ & -0.01 \\
\hline 21 IVE, Hotel, Catering \& Hairdressing & 2,587 & 0.08 \\
\hline 22 IVE, Police, Fire \& Defense Forces & $-2,314$ & -0.04 \\
\hline 23 IVE, n.e.c. & 633 & 0.01 \\
\hline 24 HVE, Teacher Training & $-10,744$ & -0.05 \\
\hline 25 HVE, Interpreter \& Translator & -998 & -0.21 \\
\hline 26 HVE, Theology & 1,013 & 0.27 \\
\hline 27 HVE, Agriculture & $-1,603$ & -0.15 \\
\hline 28 HVE, non-medical Laboratory & $-3,819$ & -0.20 \\
\hline 29 HVE, Engineering & -236 & -0.00 \\
\hline 30 Higher Transport \& Harbour & 1,031 & 0.05 \\
\hline 31 HVE, Medical Laboratory & $-3,734$ & -0.22 \\
\hline 32 HVE, Nursing \& Physiotherapy etc. & $-6,297$ & -0.13 \\
\hline 33 HVE, Commerce \& Administration & $-21,891$ & -0.23 \\
\hline 34 HVE, Business Administration Technology & -433 & -0.15 \\
\hline 35 HVE, Administrative, Legal \& Fiscal & $-1,394$ & -0.11 \\
\hline 36 HVE, Social \& Cultural & $-10,151$ & -0.15 \\
\hline 37 HVE, Hotel \& Catering Industry & $-1,413$ & -0.45 \\
\hline $38 \mathrm{HVE}$, Fine Arts & $-2,281$ & -0.08 \\
\hline 39 HVE, Police, Fire \& Defense Forces & 1,000 & 0.18 \\
\hline 40 HVE, n.e.c. & $-2,359$ & -0.20 \\
\hline $41 \mathrm{AE}$, Teacher Training & -241 & -0.02 \\
\hline $42 \mathrm{AE}$, Arts & -224 & -0.01 \\
\hline $43 \mathrm{AE}$, Theology & $-2,407$ & -0.30 \\
\hline $44 \mathrm{AE}$, Agriculture & 771 & 0.14 \\
\hline $45 \mathrm{AE}$, Mathematics \& Natural Sciences & 171 & 0.01 \\
\hline $46 \mathrm{AE}$, Engineering & 1,864 & 0.05 \\
\hline $47 \mathrm{AE}$, Veterinary \& Medical Sciences \& Dentistry & -665 & -0.02 \\
\hline $48 \mathrm{AE}$, Pharmacy & 952 & 0.54 \\
\hline $49 \mathrm{AE}$, Economics, Econometrics \& Business Administration & 2,388 & 0.10 \\
\hline $50 \mathrm{AE}$, Law \& Public Administration & $-1,797$ & -0.06 \\
\hline $51 \mathrm{AE}$, Social Sciences & $-5,041$ & -0.12 \\
\hline $52 \mathrm{AE}$, Fine Arts & 278 & 0.18 \\
\hline $53 \mathrm{AE}$, n.e.c. & $-3,927$ & -0.70 \\
\hline 54 Education, n.e.c. & 25,899 & 0.36 \\
\hline
\end{tabular}

\footnotetext{
* LVE $=$ lower vocational education

IVE $=$ intermediate vocational education

HVE $=$ higher vocational education

$\mathrm{AE}=$ academic education
}

As is often observed, there is, according to this approach, a shortage of people with only primary school. This is caused by the fact that the relative demand per occupation for this type 
of education is thought to be constant, while supply is decreasing in time. Furthermore, however, in 1985 the Dutch labour market experienced a huge increase of occupations with a relatively low educational level. This caused the relative good prospects at the market for lower skilled people in this year according the fixed coefficient approach. As mentioned earlier there are two ways to interpret the gap betwen supply and requirement for a certain type of education. Very often a difference between supply and requirement is thought to lead automatically to a corresponding level of unemployment in case of a surplus, or unfilled vacancies if there is a shortage. This rigid assumption on the functioning of the labour market is the main reason why the manpower requirement approach has often been criticised. A more practical and realistic interpretation of the manpower requirement approach views such gaps between supply and requirement, however, as an indicator of the labour market position of a type of education. If supply exceeds requirements the market position will weaken, which will reveal itself in less favourable labour contracts in terms of money, working conditions, job level etc. (see Wieling and Borghans, 1994) and only partly in unemployment. The flexibility of the labour market might enable the surplus to switch to alternative occupations, but nevertheless, this will only be possible by accepting a worsening of the labour contract conditions.

Returning to the shortage situation of lower educated people in 1985 it is important to notice that this view implies that the requirement-supply gaps are relative to the situation in 1983 . Even if there is an improvement in 1985, a bad labour market situation might remain bad. Many higher vocational types of education have a surplus. In these types of education the opposite effect occurs. The increased supply seems to suggest large problems but it may be the case that demand adjusts to the new supply situation and that these higher schooled people will face no problems in finding a job, but that they transfer the problems to lower skilled people. Furthermore, pharmacy faces huge shortages, while the academic education, n.e.c. faces even larger surpluses. These may be caused by the fact that these types of education are relatively new. In the fixed coefficient model the requirement is therefore based on a situation in which there were much less people with this education on the market. Probably many of them will, however, replace people with another education and there will be substitution.

Figure 1 illustrates the distribution of surpluses and shortages over the five educational levels (and the category without a level classification). The picture shows that all levels except primary school (and except the non-classified group) will have a surplus in 1985 according to the fixed coefficient model. The largest surplus is at the higher vocational level.

Figure 1. Fixed coefficient forecast of surpluses and shortages in 1985

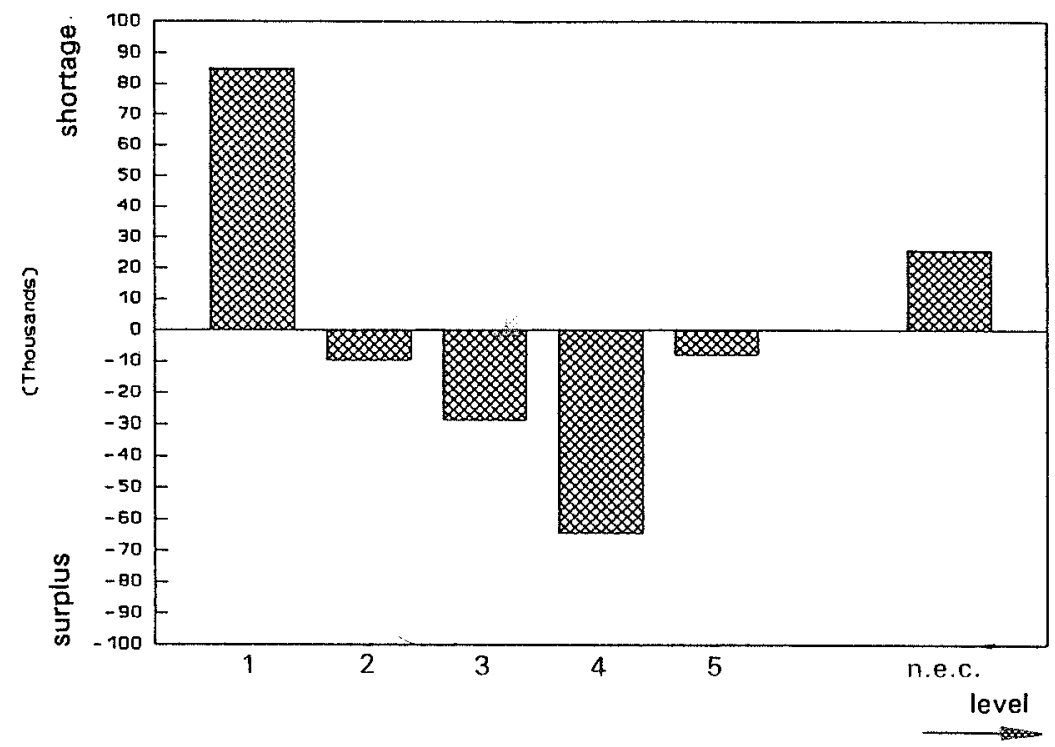


There are of course, more sophisticated ways to forecast the future requirements. A typical way to extend the model is by the introduction of explanatory variables for the requirement. At the single market level these explanatory variables are sometimes real economic variables, but in studies which investigate the labour market as a whole it is difficult to find variables that can explain the changes.

As a typical example of this approach the following model is used:

(4.5) $a_{i j}^{t}=\beta_{i j}^{0}+\beta_{i j}^{1} t+\epsilon_{i j}^{t}$

in which the trend variable $t$ equals 1 in 1979, 2 in 1981 etc. The relation (4.5) can be estimated by OLS.

(4.6) $\hat{\beta}_{i j}=\left(X^{\prime} X\right)^{-1} X^{\prime} y_{i j}$

in which

(4.7) $X=\left(\begin{array}{ll}1 & 1 \\ 1 & 2 \\ 1 & 3\end{array}\right)$

and

(4.8) $y=\left(\begin{array}{c}a_{i j}^{1} \\ a_{i j}^{2} \\ a_{i j}^{3}\end{array}\right)$

Therefore

(4.9) $\hat{\beta}_{i j}=\left(\begin{array}{l}\hat{\beta}_{i j}^{0} \\ \hat{\beta}_{i j}^{1}\end{array}\right)=\left(\begin{array}{ccc}\frac{4}{3} & \frac{1}{3} & -\frac{2}{3} \\ -\frac{1}{2} & 0 & \frac{1}{2}\end{array}\right)\left(\begin{array}{l}a_{i j}^{1} \\ a_{i j}^{2} \\ a_{i j}^{3}\end{array}\right)$

The forecast for $1985(t=4)$ equals:

(4.10) $\hat{a}_{i j}^{4}=(14) \hat{\beta}=-\frac{2}{3} a_{i j}^{1}+\frac{1}{3} a_{i j}^{2}+\frac{4}{3} a_{i j}^{3}$

Thus, OLS-estimation with a constant term and a trend variable in fact is equal to taking the weighted average of the past observations of $a_{i j}$. The weights are determined by the model (4.5). Similar to (4.5) it is possible to model the shares of educations in occupations instead of the absolute size of an education occupation combination:

(4.11) $\frac{a_{i j}^{t}}{d_{j}^{t}}=\beta_{i j}^{0}+\beta_{i f^{1}}^{t}+\epsilon_{i j}^{t}$

Table 4.2 presents the forecast qualities of the fixed coefficient method and the OLS-forecasts. For comparison also the trivial forecast $S A B$ has been added. The table shows that the forecast quality of the OLS procedure is very poor. This is a striking result, since the model used for the OLS-forecast is much more sophisticated. Model (4.11) in which the relative educational structure is modelled even predicts worse, although models like this usually are preferred (e.g. 
Peeters, 1990) because of their theoretical consistency. The instability of the OLS-models is in practice often reduced by decreasing the numbers of parameters, obtained by so-called pooling of parameters.

Table 4.2. Quality of the fixed coefficient method and two OLS-forecasts based on (4.5) and (4.11) for 1985

Method Quality (a)

\begin{tabular}{|c|c|}
\hline$S A B$ & $39710^{3}$ \\
\hline $\mathrm{FC}$ & $41610^{3}$ \\
\hline OLS (4.5) & $76110^{3}$ \\
\hline $\operatorname{OLS}(4.11)$ & $84710^{3}$ \\
\hline
\end{tabular}

The OLS forecast implicitly impose certain weights by which the past observations are weighted. The method could be generalised by other values of these weights. Table 4.3 provides the results of an estimation of the weights which optimise the quality of the forecasts. The restriction is imposed that the sum of these weights equals 1 .

Table 4.3. Estimation of optimal weights in $a_{i j}^{4}=\gamma_{1} a_{i j}^{1}+\gamma_{2} a_{i j}^{2}+\gamma_{3} a_{i j}^{3}$ (absolute) or

$$
\frac{a_{i j}^{4}}{d_{j}^{4}}=\gamma_{1} \frac{a_{i j}^{1}}{d_{j}^{1}}+\gamma_{2} \frac{a_{i j}^{2}}{d_{j}^{2}}+\gamma_{3} \frac{a_{i j}^{3}}{d_{j}^{3}} \text { (relative). Standard errors between brackets. }
$$

\begin{tabular}{lcccc}
\hline & $\gamma_{1}$ & $\gamma_{2}$ & $\gamma_{3}$ & quality (0) \\
\hline \multirow{2}{*}{ absolute } & -0.09 & 0.33 & 0.76 & $36710^{3}$ \\
relative & $(0.14)$ & $(0.17)$ & - & $36610^{3}$ \\
& -0.12 & 0.43 & 0.69 & \\
\hline
\end{tabular}

These results in comparison with table 4.2, indicate that the same as before method (SAB), or the fixed coefficient model (FC) are indeed rather good, compared to other weighted averages. $\gamma_{3}$ has a rather high coefficient. SAB would imply that $\gamma_{1}=\gamma_{2}=0$ and $\gamma_{3}=1$ in the absolute model, while FC implies $\gamma_{1}=\gamma_{2}=0$ and $\gamma_{3}=1$ in the relative model. The fact that the optimal $\gamma_{3}$ actually is lower than 1 , while $\gamma_{2}$ is above 0 can be easily explained by the measurement errors. Since $A^{3}$ is measured with an error, the forecast improves from a mixture with $A^{2}$. This mixture might, however, only cause a correction of these measurement errors, and perhaps has no economic interpretation.

The problem with extensions of the requirement-model like $(4.5)$ or $(4.11)$ is that, by extrapolating past values of the number op people with a certain educational background, working in a certain occupation to forecast future requirements, in fact observations of employment influence of the adjustment process at the labour market are used to determine the requirements. Therefore, the forecast obtained by using (4.5) en (4.11) can not be used as forecasts of the requirement but only might predict the actual levels of employment in each category. The results in table 4.2 suggest, however, that even this is not the case. It has been 
argued above that the manpower requirement approach can be interpreted in such a way that adjustment processes at the labour market can be allowed for. The rejection of the rigid manpower requirement interpretation in which no adjustments are possible, implies however also that simple estimation techniques as (4.5) and (4.11) are no longer justified. It is therefore needed to develop a model in which the gap between supply and demand can be determined in a way which takes into account the possible adjustments which took place, which are present in the data observed by the labour force survey. 


\section{INTERPRETING THE GAP BETWEEN REQUIREMENT AND SUPPLY}

In previous section it has been shown that the forecasting quality of a manpower requirement which is simply based on an extrapolation of past employment figures might not be very good. The fundamental problem of this manpower requirement model is, however, not this forecasting quality but the difficulty to interpret the results. Equation (4.2) showed that requirements do not need to equal supply. Their difference forms the gap - shortage or surplus. Before it is possible to develop a model in which the difficulties of the straight forward extrapolation model are avoided, it is necessary to answer the question, what is the meaning of such a gap? In a rigid interpretation of the manpower requirement approach it is said that the people forming the surplus will be unemployed, while the shortage constitutes unfilled vacancies (See Blaug, 1987).

Very often the manpower requirement approach is criticised because of its assumption that there is a close link between education and occupation. Shortages and surpluses on the labour market might cause employers to employ people with different types of education. Therefore, there is no need to assume that a surplus will always lead to unemployment, while shortages always lead to unfilled vacancies. People might be employed elsewhere.

This type of criticism focuses, as said before, on a very strong interpretation of the requirement model. In practice the gap between supply and requirement is not interpreted as a measure of unemployment, but rather as an indication of tension at the labour market. ${ }^{6}$ It can be shown that in a partial market model the gap between supply and requirement can indeed be interpreted as an indication of the change in the wage due to the changes in the supply and demand function.

Consider a situation in which wages clear the labour market completely. In such a situation the prospect for a certain type of education might decrease due to changing supply and demand curves, but there will never be an observable discrepancy between supply and demand. The wages will always be such that supply equals demand. The change in prospects reveals itself in a change in wages. The expression 'supply exceeds demand and therefore wages decrease' needs explanation in this context. It is only possible to speak of differences between supply and demand out of equilibrium. Therefore, a difference between supply and demand has to be interpreted as a difference between both given a certain market situation, i.e. given the wages.

In order to put this into practice a choice has to be made about the wages (or more generally the market conditions) for which supply and demand have to be determined. There are two evident solutions for this choice. Firstly, one could prescribe a certain market situation as balanced, e.g. by claiming that every academic educated person should earn a certain wage which is regarded as normal for their functions. In practice it will however be extremely difficult to define such a labour market position, but it will be even more difficult to predict supply and demand under those condition since the actual situation might be far from the ideal balanced situation. Secondly, it is of course also possible to take the labour market situation in a certain base year as a starting point for the manpower requirement approach. This second alternative

6. E.g. De Grip and Heijke (1988) and Berendsen, De Grip, and Willems (1991). 
seems easier to implement since one observation for the supply and demand at this wage is already available. That is the observation in the base year itself. Using this approach requirement is defined as the demand at the wages (or market situation) in the base year.

This definition of the base at which supply and demand are predicted implies a sharp distinction between the usefulness of the fixed-coefficient-model and the extrapolation models (4.5) and (4.11). The fixed-coefficent-model only uses the observations in the base years, while the extrapolation methods mix up these observations with data of years in which other market conditions prevailed.

A manpower requirement model based on the gap between supply and requirement at the wage in the base year, is of course only useful if indeed this gap is a good indicator of the adjustment processes which are going to take place. Consider therefore the following partial market model:

(5.1) $d^{1}=C_{D}-\beta_{D} w$

(5.2) $s^{1}=C_{S}+\beta_{s} w$

(5.3) $d^{1}=s^{1}$

in which demand $\left(d^{1}\right)$ and supply $\left(s^{1}\right)$ are a function of the wage $(w)$. The market is equilibrated by the wage in (5.3).

In a new period (2), supply and demand change due to the entrance or departure of suppliers and due to increase or decrease of demand. These changes are assumed to be changes of the scale, and therefore the parameters $C_{D}$ and $C_{S}$ and the parameters $\beta_{D}$ and $\beta_{S}$ change with the same factor, $f_{D}$ and $f_{S}$ respectively. In the new situation:

(5.4) $d^{2}=f_{D} C_{D}-f_{D} \beta_{D} w$

(5.5) $s^{2}=f_{S} C_{s}+f_{s} \beta_{s} w$

(5.6) $d^{2}=s^{2}$

In equilibrium:

(5.7) $w_{e q}^{1}=\frac{C_{D}-C_{S}}{\beta_{D}+\beta_{S}}$

and

(5.8) $w_{e q}^{2}=\frac{f_{D} C_{D}-f_{S} C_{S}}{f_{D} \beta_{D}+f_{S} \beta_{S}}$

The gap $(g)$ can be defined as the difference between supply and demand in period 2 , with the wage equal to the equilibrium wage of period 1 :

(5.9) $g=D^{2}\left(w_{e q}^{1}\right)-S^{2}\left(w_{e q}^{1}\right)$

$$
=f_{D} C_{D}-f_{S} C_{S}-\left(f_{D} \beta_{D}+f_{S} \beta_{S}\right)\left(\frac{C_{D}-C_{S}}{\beta_{D}+\beta_{S}}\right)
$$


The difference of the equilibrium wages equals:

(5.10) $w_{e q}^{2}-w_{e q}^{1}=\left(\frac{f_{D} C_{D}-f_{S} C_{S}}{f_{D} \beta_{D}+f_{S} \beta_{S}}\right)-\left(\frac{C_{D}-C_{S}}{\beta_{D}+\beta_{S}}\right)$

Therefore,

(5.11) $g=\left(w_{e q}^{2}-w_{e q}^{1}\right)\left(f_{D} \beta_{D}+f_{S} \beta_{S}\right)$

So, approximately, the gap is proportional to the change in the wage. If the gap were defined reversely, as the difference between demand and supply at the new equilibrium wage with the old supply and demand curve the proportionality relationship would be exact, i.e. the factors $f_{D}$ and $f_{S}$ which depend on the extent of the changes will disappear from the relationship.

The relationship between the gap and the change in the wage is illustrated in figure 2 .

Figure 2. An interpretation of the gap between supply and demand

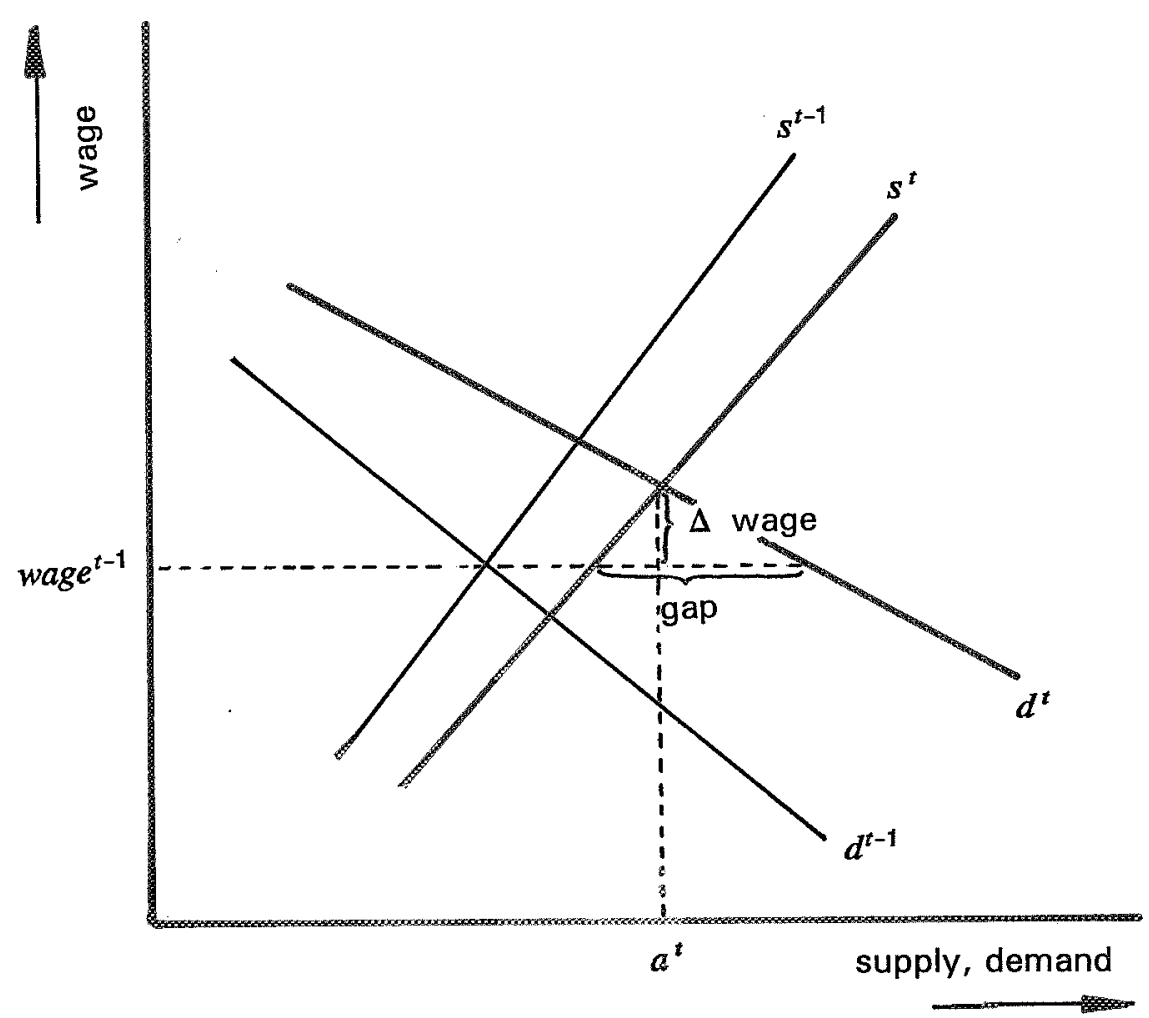

It is, therefore, no problem to interpret the requirement-approach in a partial equilibrium model. The consequence of this interpretation is only that the predicted gap will not automatically lead to unemployment or unfilled vacancies, but might give rise to other market reactions. In the model the gap will make the wage shift. The gap, however, is a good indicator of the change in the wage.

In practice the market will not be solely cleared by wages, but all types of labour market reactions might occur due to a requirement gap. The gap, in such a case, indicates the tension at the market without a unequivocal judgement how these tensions will change the labour market situation. This property makes the requirement approach very useful since it requires no 
explicit modelling of the interactions on the labour market. Furthermore, information on wages is mostly not available, so even if the market were cleared by wages, it remains, in most cases, impossible to put the wages in the analysis explicitly.

There are, however, two other problems with the manpower requirement approach. Firstly, the interpretation of figure 1 only holds in a partial market context. Labour market reaction in one segment of the market might however, influence other segments. If more market segments are investigated together, these relationships should be taken into account.

The second problem with the manpower requirement approach concerns the usual estimation practices. If the gap between supply and requirement is interpreted as in (5.9), the supply and demand figures used - the supply and demand derived from the new functions with the old equilibrium wage - are except for the base year not observed in the past. Usually, however, estimations of the requirement consist of extrapolations of the actual demand. This actual demand differs fundamentally from the requirement, as defined above. To use the interpretation it is, therefore, required to estimate the demand curve in the year of the prediction and based on this to calculate the demand which corresponds to this curve with the wages and other labour market circumstances of the base year.

Based on the interpretation of the gap between supply and requirement provided in this section, in section 7 a model is developed in which these two problems of the manpower requirement model are explicitly treated. In economic literature there is one model which also explicitly takes into account the fact that observed data reflect a situation in which labour market adjustments already have taken place. Before explaining the manpower model with substitition therefore first this RAS-model will be considered in next section. 


\section{RAS}

Although the manpower requirement approach can be understood as a method in which supply and demand (or requirement) are predicted at constant labour market conditions, it has to be recognised that in reality discrepancies between supply and demand for given market conditions will change these conditions (e.g. the wages) in order to equilibriate supply and demand again. It may therfore be a theoretically interesting construct, but it is impossible to derive this figure directly from the observations. If it is assumed that the rigid assumptions of the strict manpower requirements model do not hold, a clear distinction between the definition of the theoretical indicator, and the use of the available data has to be made. The econometric techniques which will be used should be based on the notion that in reality adjustments take place.

This should be done by explicitly stating where people of a surplus in supply will go to alternatively, and where excess demand, due to shortages will find alternative supply. The socalled RAS-model provides such a framework in which supply and demand are explicitly integrated. RAS is a method which constructs a matrix given the row and column sums such that the conditions imposed by these sums are satisfied, and such that the distance to another matrix, which is known, is minimised, according to a certain distance function. It has been shown that RAS minimises the entropy-distance-function ${ }^{7}: \sum a_{i j}^{t} \log \left(\frac{a_{i j}^{t}}{a_{i j}^{t-1}}\right)$. Kadas and Klafszky (1976) proved that this minimisation is approximately equal to estimation by minimisation of the Chi-square statistic $Q$, used in this paper. The RAS algorithm searches parameters $\boldsymbol{r}_{\boldsymbol{i}}$ for every $i$ and $q_{j}$ for every $j$ such that:

(6.1) $\operatorname{ras}_{i j}^{t}=r_{i} a_{i j}^{t-1} q_{j}$

(6.2) $\sum_{j} \operatorname{ras}_{i j}^{t}=r_{i} \sum_{j} a_{i j}^{t-1} q_{j}=s_{i}^{t}$

(6.3) $\sum_{i} \operatorname{ras}_{i j}^{t}=q_{j} \sum_{i} a_{i j}^{t-1} r_{i}=d_{j}^{t}$

Theil (1967) explains that the economic interpretation of the procedure is that a change in $a_{i j}$ is assumed to be caused by a change $\left(q_{j}\right)$ in total demand $\left(d_{j}\right)$ or a change $\left(r_{i}\right)$ in total supply $\left(s_{j}\right)$, and that there are no changes that are no special effects which are neither related tototal supply nor to total demand. These changes in total demand or total supply are, furthermore, assumed to be proportional.

Evans and Wabe (1974) show that it is possible to interpret $r_{i}$ and $q_{j}$ as a kind of price changes. In their paper education is related to industries instead of occupations. Assuming profit maximising firms in an environment of perfect competition and a Cobb-Douglas production function they show that $r_{i}$ is proportional to $\frac{w_{i}^{t-1}}{w_{i}^{t}}$, and $q_{j}$ is proportional to

7. See Blien and Tessaring (1992). The use of the entropy measure in economics stems from Theil (1967). 
$\left(\frac{p r_{j}^{t}}{p r_{j}^{t-1}}\right)\left(\frac{Y_{j}^{t}}{Y_{j}^{t-1}}\right)$, in which $p r_{j}^{t}$ is the price of production and $Y_{j}^{t}$ is the level of output of industry $j$.

The RAS model provides an interesting framework to analyse the educational structure of occupations (or industries). Bosworth, Evans, and Lindley (1974) and Evans and Lindley (1973) show that the RAS model has a rather good explanatory power compared to other models. It is, however, difficult to extend the RAS model. Furthermore, due to the strict form of the production function, the total number of workers with a certain education identifies the coefficients which are important for calculating the marginal value of the people with this educational background. To improve the forecast capability of the model it is necessary to change such rigid assumptions.

It is easy to find the appropriate values of $r_{i}$ and $q_{j}$ in the RAS-model. Starting with the basematrix of year $t-1, A^{t-1}$, both the restrictions on total supply and the restriction on total demand are not satisfied. The first step is to multiply each column with a factor such that demand totals are satisfied, comparable to the fixed coefficient model. Now only the total supply restriction is not satisfied anymore, and therefore multipliers are used to change every row such that this restriction holds. This multiplication might, however, destroy the total demand restriction again. The procedure therefore has to start again, but as has been proved, repetition of the procedure leads to convergence, with the RAS matrix as the outcome.

In the economic interpretation of the RAS model all effects are total demand, or total supply effects. E.g., if there is initially a shortage of a certain type of educated workers, their wage will go up and therefore in every occupation the number of employed with this education will decrease, without any direct effect upon people employed within this occupation with other educational background. Only indirectly their position is affected, since the increased wage will affect the production costs, what reduces the level of production and therefore reduces the demand for all types of education within that occupation. 


\section{SUBSTITUTION}

In section 5 it has been observed that the gap between supply and demand can be used as an indicator of the change in the wage. If the assumption is made that if wages do not change the educational structure of occupations remains constant, the fixed coefficient model (FC) can be interpreted as the requirement for labour given the wages in the base year. Higher wages (i.e. a positive demand-supply-gap) will cause that in the different occupations less people with this education will get hired, while lower wages (i.e. a negative gap) will cause more people to be hired. Assuming a linear relationship this leads to:

(7.1) $a_{i j}^{t}=f c_{i j}^{t}+\alpha_{i j} g_{i}^{f c}$

with $\alpha_{i j}<0$ and $\sum_{j} \alpha_{i j}=-1$

Note that although $g_{i}^{f c}$ is proportional to the wage change its dimension is number of persons. Therefore, for comparison the relative gap $\bar{g}_{i}=g_{i} / s_{i}$ is used. The second condition on $\alpha_{i j}$ guarantees that all surplus will be allocated somewhere, and that all shortages will be taken away elsewhere. This assumption therefore implies that there is no unemployment, or the unemployed should also be regarded as an 'occupation' to make the relationship hold. ${ }^{8} \alpha_{i j}$ determines the wage elasticity of demand ${ }^{9}$. This wage elasticity equals:

$$
\frac{\left(\frac{d a_{i j}}{d s_{i}+g_{i}}\right)}{\left(\frac{a_{i j}}{s_{i}}\right)}=\frac{\alpha_{i j}}{a_{i j}} \cdot s_{i}
$$

The demand adjustments to changes in wages are such that the allocation of people over the occupations is consistent with total supply. It may however be inconsistent with total demand. To restore the demand-consistency substitution is needed. For all people employed due to changes in the wage people with other educational background in the same occupation have to leave and v.v. Since these changes in employment are not directly caused by changes in wages, and therefore the relative wages of these educations remain unchanged, it is, for the time being, reasonable to assume a proportional change in employment to occur. An increase (or decrease) in demand of $\alpha_{i} p_{i}$ therefore causes a negative (positive) substitution for every education $k \neq i$ in occupation $j$ of:

(7.3) $p s_{k j}(i)=-\alpha_{i j} g_{i} \frac{f c_{k j}}{\sum_{l \neq i} f c_{l j}}=-\alpha_{i j} g_{i} \frac{f c_{k j}}{d_{j}-f c_{i j}}$

8. See appendix 3 for the treatment of unemployment.

9. Since (7.1) implicity assumes that the wage only depends on educational background and not on the occupation in which someone is working, supply must be completely elastic between different jobs. Therefore, supply is completely determined by the wage, or wages are such that workers are indifferent between jobs and the gap as an indication of the wage should include the wage compensation (i.e. the non-pecuniary payments). 
The corresponding elasticity equals:

$$
\frac{\left(\frac{\mathrm{d} a_{k j}}{\mathrm{~d} s_{i}+g_{i}}\right)}{\left(\frac{a_{k j}}{s_{i}}\right)}=-\alpha_{i j} \frac{f c_{k j}}{d_{j}-f c_{i j}} \frac{s_{i}}{a_{k j}}
$$

For type of education $k$ in occupation $j$ in total the substitution equals:

(7.5) $p s_{k j}=\sum_{i \neq k} p s_{k j}(i)$

and for education $k$ the total substitution equals:

(7.6) $p s_{k}=\sum_{j} p s_{k j}=\sum_{j} \sum_{i \neq k} p s_{k j}(i)$

This type of education is therefore, due to the wage changes is other types of education, confronted with a change in demand. Types of education which have lower wages will take away demand from $k$, while types of education will higher wages will cause additional demand for $k$. This substitution may decrease or increase the gap between supply and demand, and therefore also the price may change:

(7.7) $g_{i}^{s}=g_{i}^{f c}+p s_{i}$

and (7.1) has to be changed, to count for this substitution into:

(7.8) $a_{i j}^{t}=f c_{i j}^{t}+p s_{i j}+\alpha_{i j} g_{i}^{s}$

In this system it is assumed that the gap between supply and requirement, in which demand consists of both the initial fixed coefficient demand and substitution demand arising from the wage changes of other types of education, will be completely redistributed over the occupation due to a change of wage. This effect should however not be treated as an additional requirement, since it is caused by an adjustment of the wage. In fact it represents not a shift of the demand curve but a shift on the demand curve in order to equilibriate supply and demand.

The total Manpower with Substition (MPS) system therefore becomes:

(7.9) $a_{i j}^{t}=f c_{i j}^{t}+p s_{i j}+\alpha_{i j} g_{i}^{s}$

(7.10) $g_{i}^{s}=g_{i}^{f c}+p s_{i}$

(7.11)

$p s_{k j}(i)=-\alpha_{i j} g_{i} \frac{f c_{k j}^{t}}{d_{j}-f c_{i j}^{t}}$

(7.12) with $p s_{k j}=\sum_{i \neq k} p s_{k j}(i)$

(7.13) and $p s_{k}=\sum_{j} p s_{k j}$

In this system $a_{i j}^{t}$ is explained by the exogenous variables $g_{i}^{f c}, f c_{i j}^{t}$, and $d_{i}$, and the constants $\alpha_{i j} \cdot g_{i}^{s}$ and $p s_{i j}$ are endogenous variables. 
Figure 3 graphically shows the relationships of model $(7.9)-(7.13)$.

Figure 3. The manpower model with substitution (Thick lines indicate the additions to the usual manpower requirement model)

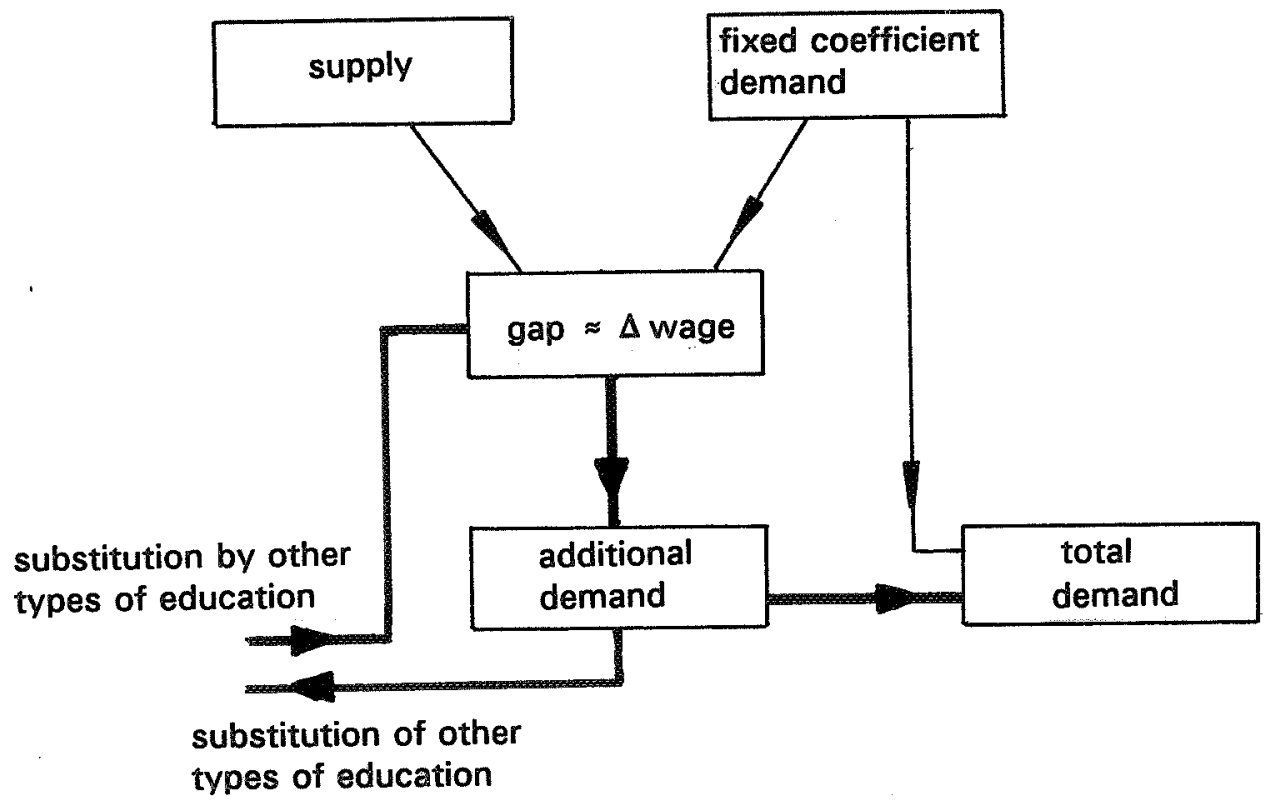




\section{CALCULATING $g_{i}^{s}$ AND $\alpha_{i j}$}

To use the model of section 7 for forecasting the future educational structure of occupation first the values of $\alpha_{i j}$ have to be determined. This can be done either by estimation or by assumption. A straightforward assumption to avoid estimation is to put

(8.1) $\alpha_{i j}=-\frac{a_{i j}^{t-1}}{s_{i}^{t-1}}$

This rule satisfies the condition that $\sum \alpha_{i j}=-1$ and means that additional supply will be distributed proportional to the existing ${ }^{j}$ distribution of that education over the occupations. According to (7.2) the elasticity equals approximately -1 . A further extension of this assumption is a model in which $\alpha_{i j}$ is also dependent on some economic variables. The parameters of this relationship can be estimated. This method is used in the second extension of section 10.

The manpower model with substitution, together with assumption (8.1) can be regarded as a linear approximation of the RAS-model. This can be shown by writing:

(8.2) $a_{i j}^{t+1}=r_{i} a_{i j}^{t} q_{i}=\left(1+\mu_{i}\right) a_{i j}^{t}\left(1+\eta_{j}\right)=a_{i j}^{t}+\mu_{i} a_{i j}^{t}+\eta_{i} a_{i j}^{t}+\mu_{i} a_{i j}^{t} \eta_{j}$

The predicted $a_{i j}^{t+1}$ therefore equals $a_{i j}^{t}$ in the base year, plus a term which indicates the effects due to changes in the wages and a term which indicates the substitution. Since these latter two effects are proportional to $a_{i j}^{t}$ they are equal to the MPS-model. The difference is the fourth term, the interaction effect, which is not included in MPS.

Based on the educational structure of two years in the past, $t_{1}$ and $t_{2}$, it is however also possible to calculate exact values of $\alpha_{i j}$ which generate, based on the educational structure of $t_{1}$, the structure of $t_{2}$. This can be done by an iterative procedure. It starts with $p s_{i j}=0$.

Then

(8.3) $\alpha_{i j} g_{i}^{s}=a_{i j}^{t}-f c_{i j}^{t}-p s_{i j}$

can be calculated. This makes it possible to calculate

$$
p s_{i j}=\sum_{k \neq i} p s_{i j}(k)=\sum_{k \neq i}-\alpha_{i j} g_{i}^{s} \frac{f c_{i j}^{t}}{d_{j}-f c_{k j}^{t}}
$$

These values of $p s_{i j}$ can be used to calculate $\alpha_{i j} g_{i}^{s}$ again etc. until convergence is reached. Based on the values of $p s_{i j}$ it is possible to calculate $g_{i}^{s}$ and therefore also possible to calculate $\alpha_{i j}$.

Table 8.1 provides $\boldsymbol{g}_{i}^{s}$ for 1985 based on 1983-1985. The shortage for primary school education reduces very slightly. The large shortage for primary schooled people decreases. 
Table 8.1. The gap between demand and supply in 1985 calculated by the manpower model (based on possibly positive values for $\alpha_{i j}$ )

\begin{tabular}{|c|c|c|}
\hline & gap & relative gap \\
\hline 1 Primary Education & 64,052 & 0.09 \\
\hline 2 Lower General Secondary Education & 37,095 & 0.10 \\
\hline 3 LVE, Agriculture & 3,033 & 0.03 \\
\hline 4 LVE, Technical & $-4,257$ & -0.01 \\
\hline 5 LVE, Transport \& Harbour & $-6,782$ & -0.21 \\
\hline 6 LVE, Commerce \& Administration & $-33,092$ & -0.23 \\
\hline 7 LVE, Community Care, Hotel \& Catering & 6,862 & 0.03 \\
\hline 8 LVE, Security & $-1,892$ & -0.34 \\
\hline 9 LVE, n.e.c. & $-7,854$ & -0.38 \\
\hline 10 Higher General Secondary Education & 377 & 0.00 \\
\hline $11 \mathrm{IVE}$, Agriculture & $-2,182$ & -0.02 \\
\hline 12 IVE, Non-Medical laboratory & -414 & -0.06 \\
\hline 13 IVE, Engineering & 13,687 & 0.02 \\
\hline 14 IVE, Transport \& Harbour & 546 & 0.01 \\
\hline 15 IVE, Medical Laboratory & $-1,257$ & -0.06 \\
\hline 16 IVE, Nursing \& Para-medical services & 484 & 0.00 \\
\hline 17 IVE, Commerce \& Administration & $-28,044$ & -0.05 \\
\hline 18 IVE, Administrative, legal \& Fiscal & $-2,243$ & -0.05 \\
\hline 19 IVE, Social \& Cultural & $-1,372$ & -0.05 \\
\hline 20 IVE, Community Care & 569 & 0.00 \\
\hline 21 IVE, Hotel, Catering \& Hairdressing & 2,428 & 0.07 \\
\hline 22 IVE, Police, Fire \& Defense Forces & $-1,131$ & -0.02 \\
\hline 23 IVE, n.e.c. & -34 & -0.00 \\
\hline 24 HVE, Teacher Training & $-7,057$ & -0.03 \\
\hline 25 HVE, Interpreter \& Translator & $-1,002$ & -0.21 \\
\hline 26 HVE, Theology & 492 & 0.13 \\
\hline 27 HVE, Agriculture & $-1,423$ & -0.13 \\
\hline $28 \mathrm{HVE}$, non-medical Laboratory & $-3,783$ & -0.20 \\
\hline 29 HVE, Engineering & 600 & 0.01 \\
\hline 30 Higher Transport \& Harbour & 960 & 0.05 \\
\hline 31 HVE, Medical Laboratory & $-3,438$ & -0.21 \\
\hline 32 HVE, Nursing \& Physiotherapy etc. & $-5,500$ & -0.11 \\
\hline 33 HVE, Commerce \& Administration & $-20,976$ & -0.22 \\
\hline 34 HVE, Business Administration Technology & -440 & -0.15 \\
\hline 35 HVE, Administrative, Legal \& Fiscal & $-1,432$ & -0.11 \\
\hline 36 HVE, Social \& Cultural & $-8,881$ & -0.13 \\
\hline 37 HVE, Hotel \& Catering Industry & $-1,404$ & -0.44 \\
\hline 38 HVE, Fine Arts & $-1,771$ & -0.06 \\
\hline 39 HVE, Police, Fire \& Defense Forces & 886 & 0.16 \\
\hline 40 HVE, n.e.c. & $-2,384$ & -0.20 \\
\hline $41 \mathrm{AE}$, Teacher Training & -713 & -0.05 \\
\hline $42 \mathrm{AE}$, Arts & -623 & -0.04 \\
\hline $43 \mathrm{AE}$, Theology & $-1,814$ & -0.23 \\
\hline $44 \mathrm{AE}$, Agriculture & 624 & 0.12 \\
\hline $45 \mathrm{AE}$, Mathematics \& Natural Sciences & 211 & 0.01 \\
\hline $46 \mathrm{AE}$, Engineering & 883 & 0.02 \\
\hline $47 \mathrm{AE}$, Veterinary \& Medical Sciences \& Dentistry & -844 & -0.02 \\
\hline $48 \mathrm{AE}$, Pharmacy & 915 & 0.52 \\
\hline $49 \mathrm{AE}$, Economics, Econometrics \& Business Administration & 2,048 & 0.08 \\
\hline $50 \mathrm{AE}$, Law \& Public Administration & $-1,350$ & -0.05 \\
\hline $51 \mathrm{AE}$, Social Sciences & $-5,009$ & -0.13 \\
\hline $52 \mathrm{AE}$, Fine Arts & 229 & 0.15 \\
\hline $53 \mathrm{AE}$, n.e.c. & $-3,948$ & -0.71 \\
\hline 54 Education, n.e.c. & 27,364 & 0.38 \\
\hline
\end{tabular}


Most of the surpluses in academic education decrease. A good example of substitution is provided by theology at HVE and academic level. Table 4.1 indicates that, in the fixed coefficient forecast, at HVE level there is a large shortage while at academic level there is a large surplus of theologians. Due to substitution between these two categories the surplus at academic level decreases, however, from -0.30 to -0.27 , while the shortage at higher vocational level decreases from 0.27 to 0.13 . Measured in persons this substitution is not very substantial, but it illustrates clearly the substitution mechanism. The problem of the gap as presented in table 8.1 is that they depend on the calculation of $\alpha_{i j}$. As will be shown later, the procedure to calculate $\alpha_{i j}$ described in this section provides results with a very bad forecasting quality. Therefore the calculated $g_{i}$ 's also should be treated with care. In general the algorithm seems to find results for $g_{i}$ which smooth the surpluses and shortages.

The procedure described above does not guarantee that $\alpha_{i j} \leq 0$. Therefore estimations of $\alpha_{i j}$ which are positive can be put equal to 0 , and after this adjustment the other $\alpha_{i j}$ are rescaled such that $\sum_{j} \alpha_{i j}=-1$ again. 


\section{FORECASTING}

Based on estimations of $\alpha_{i j}$ and based on a year in the past for which the educational structure of occupations is known (the most recent year) it is possible to forecast the future allocation of (known or predicted) supply over (known or predicted) demand.

This again can be done by an iterative procedure. Starting with $p s_{i j}=0$ it is possible to calculate

(9.1) $a_{i j}^{t+1}=f c_{i j}^{t+1}+p s_{i j}+\alpha_{i j}\left(g_{i}^{f c}+p s_{i}\right)$

This makes it possible to calculate $p s_{i j}$ which can be used to calculate $a_{i j}$ again, etc until convergence is reached.

The results in table 9.1, which are based on assumption (8.1), illustrate the typical labour market situation in 1985. As mentioned earlier in 1985 there was a huge increase of occupations at a low educational level, resulting in a large increase of the demand for lower skilled workers and a decrease in the demand for higher skilled workers. Since substitution between higher and lower skilled workers is relatively low compared to substitution within these groups, the forecasts of the manpower model after substitution even indicate an increased matching problem. In the case in which two substitutes have an opposite gap predicted by the fixed coefficient model, the manpower model will forecast a lower surplus and shortage. If, however, within a group of substitutes every education is in a bad position the situation will even further worsen. In such a case a relatively large supply will not only be confronted with a relative low demand according to the fixed coefficient model, but will also be confronted with the pressure of the substitutes which also face a bad labour market situation.

Figure 4 provides the distribution of shortages and surplus according to the manpower forecast (comparable to figure 1). Due to substitution from the primary school level the position of lower vocational educations improves substantial. The position of higher vocational education and academic education becomes worse due to the general surplus situation within these levels, and due to the relatively low substitution possibilities with the lower educational levels.

Figure 4. Shortage and surpluses after substitution in the basic MPS model

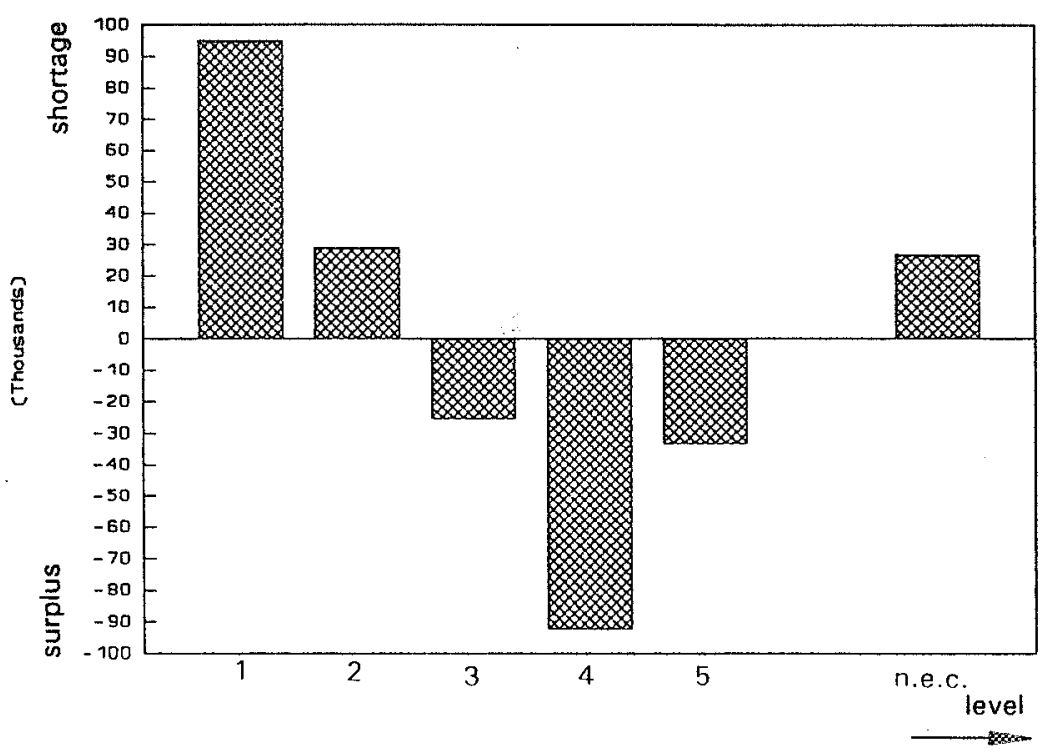


Table 9.1. The gap between demand and supply in 1985 forecasted by the manpower model with (8.1) (MPS-2)

\begin{tabular}{|c|c|c|}
\hline & gap & relative gap \\
\hline 1 Primary Education & 95,004 & 0.14 \\
\hline 2 Lower General Secondary Education & 38,746 & 0.10 \\
\hline 3 LVE, Agriculture & 8,382 & 0.08 \\
\hline 4 LVE, Technical & 16,758 & 0.03 \\
\hline 5 LVE, Transport \& Harbour & $-5,653$ & -0.17 \\
\hline 6 LVE, Commerce \& Administration & $-33,545$ & -0.23 \\
\hline 7 LVE, Community Care, Hotel \& Catering & 13,681 & 0.06 \\
\hline 8 LVE, Security & $-2,060$ & -0.37 \\
\hline 9 LVE, n.e.c. & $-7,395$ & -0.35 \\
\hline 10 Higher General Secondary Education & $-5,481$ & -0.02 \\
\hline 11 IVE, Agriculture & 1,569 & 0.02 \\
\hline 12 IVE, Non-Medical laboratory & -574 & -0.09 \\
\hline $13 \mathrm{IVE}$, Engineering & 25,753 & 0.05 \\
\hline 14 IVE, Transport \& Harbour & 1,551 & 0.04 \\
\hline 15 IVE, Medical Laboratory & $-2,092$ & -0.10 \\
\hline 16 IVE, Nursing \& Para-medical services & $-2,327$ & -0.02 \\
\hline 17 IVE, Commerce \& Administration & $-34,616$ & -0.06 \\
\hline 18 IVE, Administrative, legal \& Fiscal & $-4,221$ & -0.10 \\
\hline 19 IVE, Social \& Cultural & $-3,435$ & -0.13 \\
\hline 20 IVE, Community Care & 1,008 & 0.00 \\
\hline 21 IVE, Hotel, Catering \& Hairdressing & 3,037 & 0.09 \\
\hline 22 IVE, Police, Fire \& Defense Forces & $-2,546$ & -0.04 \\
\hline 23 IVE, n.e.c. & $-2,896$ & -0.07 \\
\hline 24 HVE, Teacher Training & $-21,782$ & -0.10 \\
\hline 25 HVE, Interpreter \& Translator & $-1,380$ & -0.29 \\
\hline 26 HVE, Theology & -310 & -0.08 \\
\hline 27 HVE, Agriculture & $-1,869$ & -0.17 \\
\hline 28 HVE, non-medical Laboratory & $-4,254$ & -0.23 \\
\hline 29 HVE, Engineering & -792 & -0.01 \\
\hline 30 Higher Transport \& Harbour & 1,188 & 0.06 \\
\hline 31 HVE, Medical Laboratory & $-5,112$ & -0.31 \\
\hline 32 HVE, Nursing \& Physiotherapy etc. & $-9,618$ & -0.20 \\
\hline 33 HVE, Commerce \& Administration & $-24,004$ & -0.25 \\
\hline 34 HVE, Business Administration Technology & -546 & -0.19 \\
\hline 35 HVE, Administrative, Legal \& Fiscal & $-2,388$ & -0.19 \\
\hline 36 HVE, Social \& Cultural & $-14,626$ & -0.22 \\
\hline 37 HVE, Hotel \& Catering Industry & $-1,416$ & -0.45 \\
\hline 38 HVE, Fine Arts & $-3,379$ & -0.12 \\
\hline 39 HVE, Police, Fire \& Defense Forces & 626 & 0.11 \\
\hline 40 HVE, n.e.c. & $-2,623$ & -0.22 \\
\hline $41 \mathrm{AE}$, Teacher Training & $-2,985$ & -0.21 \\
\hline $42 \mathrm{AE}$, Arts & $-3,203$ & -0.19 \\
\hline $43 \mathrm{AE}$, Theology & $-2,907$ & -0.37 \\
\hline $44 \mathrm{AE}$, Agriculture & 279 & 0.05 \\
\hline $45 \mathrm{AE}$, Mathematics \& Natural Sciences & $-2,317$ & -0.10 \\
\hline $46 \mathrm{AE}$, Engineering & -116 & -0.00 \\
\hline $47 \mathrm{AE}$, Veterinary \& Medical Sciences \& Dentistry & $-4,706$ & -0.13 \\
\hline $48 \mathrm{AE}$, Pharmacy & 562 & 0.32 \\
\hline $49 \mathrm{AE}$, Economics, Econometrics \& Business Administration & 157 & 0.01 \\
\hline $50 \mathrm{AE}$, Law \& Public Administration & $-3,885$ & -0.14 \\
\hline $51 \mathrm{AE}$, Social Sciences & $-9,911$ & -0.25 \\
\hline $52 \mathrm{AE}$, Fine Arts & 9 & 0.01 \\
\hline $53 \mathrm{AE}$, n.e.c. & $-4,102$ & -0.73 \\
\hline 54 Education, n.e.c. & 26,766 & 0.37 \\
\hline
\end{tabular}


Table 9.2 provides an evaluation of these forecasts. The forecasts use estimates of $\alpha_{i j}$ based on $t-2$ and $t-4$ and predict the structure of $t$. Firstly, the table provides estimations of the measurement errors based on table 3.4 .

For comparison also the forecast results of other models have been added. The table provides results for SAB, FC, and RAS. The manpower model with substitution developed in section 7 is labelled MPS. In MPS-1, $\alpha$ has been calculated according to the method of section 8 , based on data of two past years. Therefore the table provides no forecast of MPS-1 for 1981. In MPS-2 $\alpha_{i j}=-\frac{a_{i j}^{t-1}}{s_{i}^{t-1}}($ see $(8.1))$.

Between brackets the relative quality of each forecast, compared to SAB has been added. In this comparison the measurement error has been subtracted from the quality figures.

The table shows that the fixed coefficient model is not really an improvement compared to SAB. In 1983 FC performs $34 \%$ better, but in 1981 and 1985 the results are worse. RAS is a real improvement of 40 to $60 \%$. MPS-2 gives results which are comparable to RAS, but MPS-1, in which $\alpha$ has been calculated based on past data has a very low forecasting quality, even worse than SAB. Apparently the calculation of $\alpha$ leads to much noise in the results.

Table 9.2. The quality of some forecast methods. Quality relative to SAB without measurement error between brackets

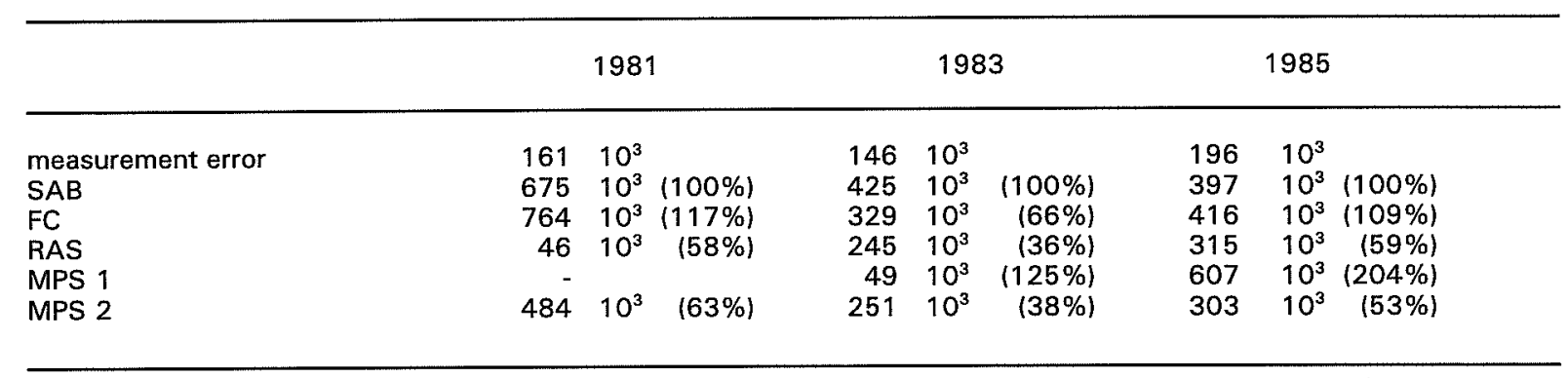




\section{EXTENSIONS OF THE MANPOWER FORECAST MODEL}

The manpower forecast model of section 7 has a forecast quality which is comparable with the RAS model. An advantage of the MPS model is however that the structure of the model makes it possible to extent the model with economic mechanisms more easily than the RAS model does. In this section three such extensions are shown which are all based on the variables educational level and occupational level, introduced in section 2.

It is possible to include economic mechanisms at three places in the model. Firstly, the substitution process might not be equally for all educations, but might be explained by economic variables. Secondly, the wage elasticities of a certain education might differ for different occupations and not equal -1 as is assumed in MPS-2. Also these deviations could be explained by economic variables. Thirdly, it is possible to leave the fixed coefficient model as base for the substitution process, and include some additional exogenous changes in the demand for certain types of education in certain occupations, again depending on economic variables. In this section examples are provided of these three types of extensions.

\section{The substitution process}

Equation (7.3) states that in the case the demand for education $k$ in occupation $j$ increases or decreases because of change in the wage, substitution to education $i$ will be proportional to the number of people in this education.

(10.1) $p s_{i j}(k)=-\alpha_{i j} g_{i} \frac{f c_{i j}^{t}}{d_{j}-f c_{k j}^{t}}=-\alpha_{i j} g_{i}^{s} \frac{f c_{i j}^{t}}{\sum_{i \neq k} f c_{i j}^{t}}$

The idea behind the first extension is that in case of increasing demand for education $k$, and thus a negative effect for other educations, people with an educational level which differs much from the occupational level have a larger probability to leave than people with an educational level close to the occupational level. In the case of a decreasing demand, and a positive substitution effect for other educations, the opposite might be the case. People with an educational level close to the occupational level will have relatively a larger probability to be a substitute than others. Employers might use labour market mobility to adjust their working force to the level they actually require.

Therefore in case of a decrease in demand due to an increased wage for education $k$ substitution is assumed to be proportional to:

(10.2) $f_{i j}^{t}=f c_{i j} e^{\left.\left(-\gamma_{1} \mid l_{l}-t_{j}^{t-1}\right)\right)}$

and in case of an increase:

(10.3) $f_{i j}=f c_{i j} e^{\left(-\gamma_{2}\left|t_{i}-t_{j}^{t-1}\right|\right)}$

Therefore, $\gamma_{1}$ is expected to be positive, while $\gamma_{2}$ is expected to be negative. (10.1) is replaced by:

$$
p s_{i j}(k)=-\alpha_{i j} g_{i}^{s} \frac{f_{i j}^{t}}{\sum_{i \neq \hbar} f_{i j}^{t}}
$$

An implicit assumption in this model is that a too high educational level will have the same effects as a too low educational level compared to the occupational level. the specification is 
(10.4) $p s_{i j}(k)=-\alpha_{i j} g_{i}^{s} \frac{f_{i j}^{t}}{\sum_{i \neq k} f_{i j}^{t}}$

symmetric in this respect. Table 10.1 presents estimation results ${ }^{10}$.

Table 10.1. Estimation results of (10.2) and (10.3); standard errors between brackets

\begin{tabular}{|c|c|c|c|c|}
\hline & 1981 & & 1983 & 1985 \\
\hline quality & $48410^{3}$ & $(99.9 \%)$ & $25010^{3} \quad(99.8 \%)$ & $29510^{3} \quad(97 \%)$ \\
\hline$\gamma_{1}$ & $\begin{array}{c}0.26 \\
(0.244)\end{array}$ & & $\begin{array}{c}0.10 \\
(0.283)\end{array}$ & $\begin{array}{c}1.92 \\
(0.484)\end{array}$ \\
\hline$\gamma_{2}$ & $\begin{array}{r}0.14 \\
(0.170)\end{array}$ & & $\begin{array}{l}-0.51 \\
(0.125)\end{array}$ & $\begin{array}{l}-0.16 \\
(0.157)\end{array}$ \\
\hline
\end{tabular}

The results are rather poor. The parameters are not very stable in time and mostly they do not differ significantly from 0 . An exception to this is $\gamma_{1}=1.92$ in 1985 . This extremely high coefficient can again be explained by the huge increase of the employment of people with only primary school. The extreme value of the parameter reduces substitution of educations of another level, to diminish the shortage at the lowest level, almost to zero. This indicates that the increase of participation of low educated people in 1985 was probably not caused by an increase in demand for certain occupations, but that the rise in these occupations is caused by an increased attractiveness to employ (or an increased willingness to participate) these low educated people.

Furthermore, the forecast quality of the model does not improve significantly. The percentages refer to the basic manpower model MPS-2, and do not correct for measurement errors, but even in regard of the measurement errors improvements of less than $1 \%$ are not impressive. Only for 1985 some significant improvement of $3 \%$ is obtained.

\section{The wage elasticities}

A second approach to extend the basic model is by adjustments to the structure of the wage elasticities. In MPS-2 the assumption is made that

(10.5) $\alpha_{i j}=-\frac{a_{i j}^{t-1}}{s_{i}^{t-1}}=-\frac{a_{i j}^{t-1}}{\sum_{j} a_{i j}^{t-1}}$

10. The parameters have been estimated by non-linear least squares. Standard errors have been calculated conform Judge et al. (1980, pp. 723-725) by $\sum_{\gamma}=\hat{\sigma}^{2}(Z(\gamma) / Z(\gamma))^{-1}$ in which $Z_{i j}(\gamma)=\frac{\mathrm{d} \hat{a}_{i j}(\gamma)}{\mathrm{d} \gamma} \frac{1}{\sqrt{\hat{a}_{i j}}}$ and $\hat{\sigma}^{2}=\frac{Q(y)}{T-K}$ 
This implies an elasticity of -1 . By defining
(10.6) $\quad \tilde{a}_{i j}=a_{i j}^{t-1} e^{\left(-\gamma_{1}\left(l_{i}-l_{j}^{t-1}\right)\right)} \quad$ if $l_{i}>l_{j}^{t-1}$
(10.7) $\quad \tilde{a}_{i j}=a_{i j}^{t-1} e^{\left(-\mathrm{-}_{2}\left(l_{f}^{t-1}-l_{i}\right)\right)} \quad$ if $l_{i} \leq l_{j}^{t-1}$

with

(10.8) $\alpha_{i j}=-\frac{\tilde{a}_{i j}}{\sum_{j} \tilde{a}_{i j}}$

the possibility is created that the elasticity of demand increases (i.e. comes closer to 0 ) if the educational level deviates more from the occupational level. In this example there is an asymmetry between too low levels of education and too high levels of education. $\gamma_{1}$ represents the higher level educations and $\gamma_{2}$ the lower level educations, compared to the occupational level. Table 10.2 presents the estimation results.

Table 10.2. Estimation results of (10.8); standard errors between brackets

\begin{tabular}{|c|c|c|c|}
\hline & 1981 & 1983 & 1985 \\
\hline quality & $47810^{3} \quad(98.6 \%)$ & $246 \quad 10^{3} \quad(97.8 \%)$ & $29110^{3} \quad(96.1 \%)$ \\
\hline$\gamma_{1}$ & $\begin{array}{l}-0.22 \\
(0.123)\end{array}$ & $\begin{array}{l}-0.34 \\
(0.139)\end{array}$ & $\begin{array}{c}0.93 \\
(0.137)\end{array}$ \\
\hline$\gamma_{2}$ & $\begin{array}{c}0.63 \\
(0.154)\end{array}$ & $\begin{array}{c}-0.75 \\
(0.076)\end{array}$ & $\begin{array}{c}-0.02 \\
(0.130)\end{array}$ \\
\hline
\end{tabular}

The parameters of 1981 provide a situation as might be expected. Higher educational levels are more easily offered a job than lower educational levels. Therefore the parameter $\gamma_{1}$ is negative, stimulating the inflow of higher levels, and $\gamma_{2}$ is positive, reducing the inflow of lower levels. Both parameters are significant, but the forecast quality only improves $1.4 \%$. In 1985 the parameters have the reverse sign. $\gamma_{1}$ is again rather high, what implies a very low inflow of higher educated. The forecast quality improves almost $4 \%$.

\section{Exogenous changes in demand}

Finally, it is possible to specify a model in which the fixed coefficient model is extended as basis for the demand side of the model. Instead of the fixed coefficient assumption it is allowed that some exogenous developments in demand might occur. Therefore, the fixed coefficient calculation is not based on $a_{i j}^{t-1}$ but on:

(10.9) $\bar{a}_{i j}=a_{i j}^{t-1} e^{\left(-\gamma_{1}\left(5-l_{i}\right)\right)} e^{\left(-\gamma_{2}\left|l_{i}-l_{i}^{t-1}\right|\right)}$

$\gamma_{1}$ represents a tendency to require higher levels of education and $\gamma_{2}$ represents the tendency to demand for educational levels which fit closer to the occupational level. Therefore, both parameters might be expected to be positive. Table 10.3 provides the estimation results. 
$-35-$

Table 10.3. estimation results of (10.9); standard errors between brackets

\begin{tabular}{|c|c|c|c|c|}
\hline & 1981 & & 1983 & 1985 \\
\hline quality & $47810^{3}(98.6 \%)$ & $24610^{3}$ & $(97.7 \%)$ & $28910^{3}(95.7 \%)$ \\
\hline$\gamma_{1}$ & $\begin{array}{c}0.15 \\
(0.030)^{-1}\end{array}$ & & $\begin{array}{c}0.15 \\
(0.027)\end{array}$ & $\begin{array}{r}-0.15 \\
(0.037)\end{array}$ \\
\hline$\gamma_{2}$ & $\begin{array}{c}0.04 \\
(0.020)\end{array}$ & & $\begin{array}{c}0.00 \\
(0.015)\end{array}$ & $\begin{array}{c}0.10 \\
(0.017)\end{array}$ \\
\hline
\end{tabular}

The table shows that in 1981 and 1983 the parameters have the expected sign. The significance (except for $\gamma_{2}$ in 1983, which equals 0 ) is very high. The results indicate a relative high increase in the demand for higher educated workers together with a lower tendency to adjust demand to the average level of the working force. In 1985, again, the opposite results appear. There is a tendency to demand lower levels while the tendency to hire only those who meet the required level increases.

Furthermore, the improvements of the forecast quality of this third model are the largest, compared to the other two extensions, although the reduction of the forecast error still is rather small.

Figure 5. Adjusted 'fixed coefficient' forecasts for 1985

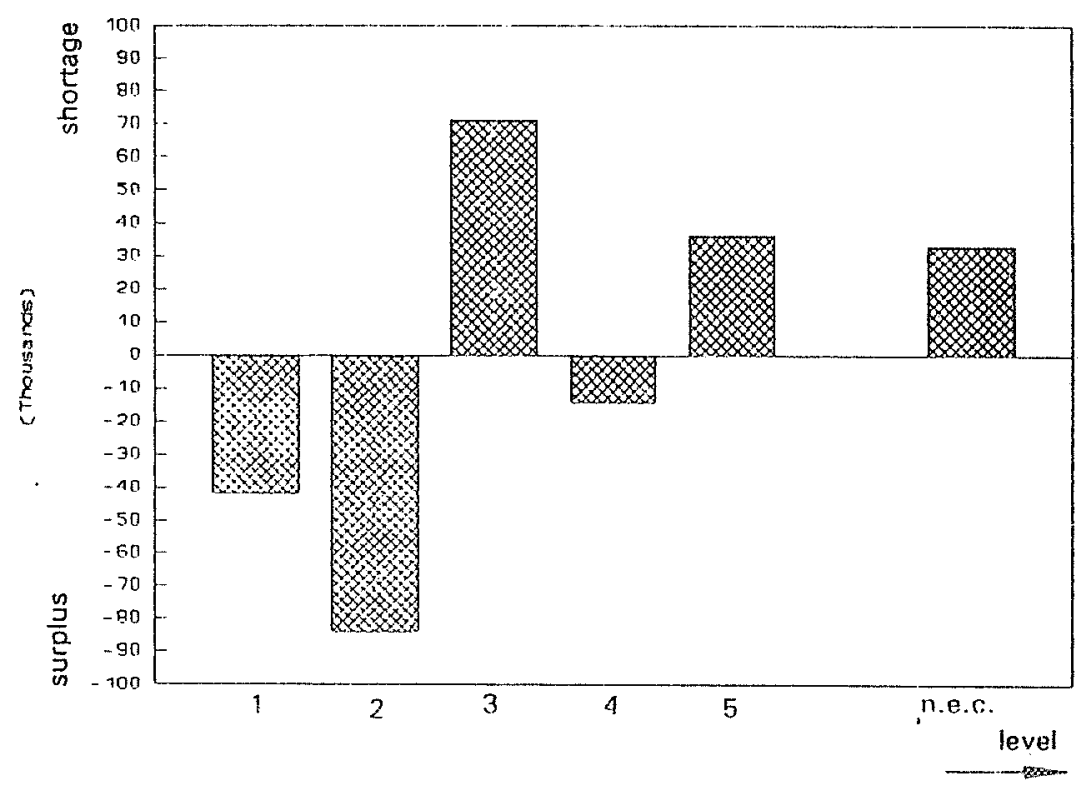

Figure 5 shows the surpluses and shortages of the adjusted fixed-coefficient model (10.9) using the 1983 parameters as a forecast for 1985, and figure 6 provides the same surpluses and shortages after substitution. The figures indicate an increase in the demand for higher levels and a decrease in demand for lower levels. It seems to be the case that in order to get plausible results, the manpower model at least has to take into account this upgrading process. Since the 
MPS model is primarily used to forecast gaps between supply and demand the large difference with figure 4 shows that small changes in explanatory power regarding actual mobility between occupations might go together with large changes in the prospects. In order to improve the models further it might therefore be important to evaluate not only the changes in the actual employment situation of different types of education, as predicted by the MPS model, but to proof the validity of the model by investigating the ability of the calculated gaps to predict changes in the actual labour market position of primarily newcomers on the market, measured by their wages, job-level etc. This approach is followed by Wieling and Borghans (1994).

Figure 6. Adjusted 'fixed coefficient' forecasts for 1985 after substitution

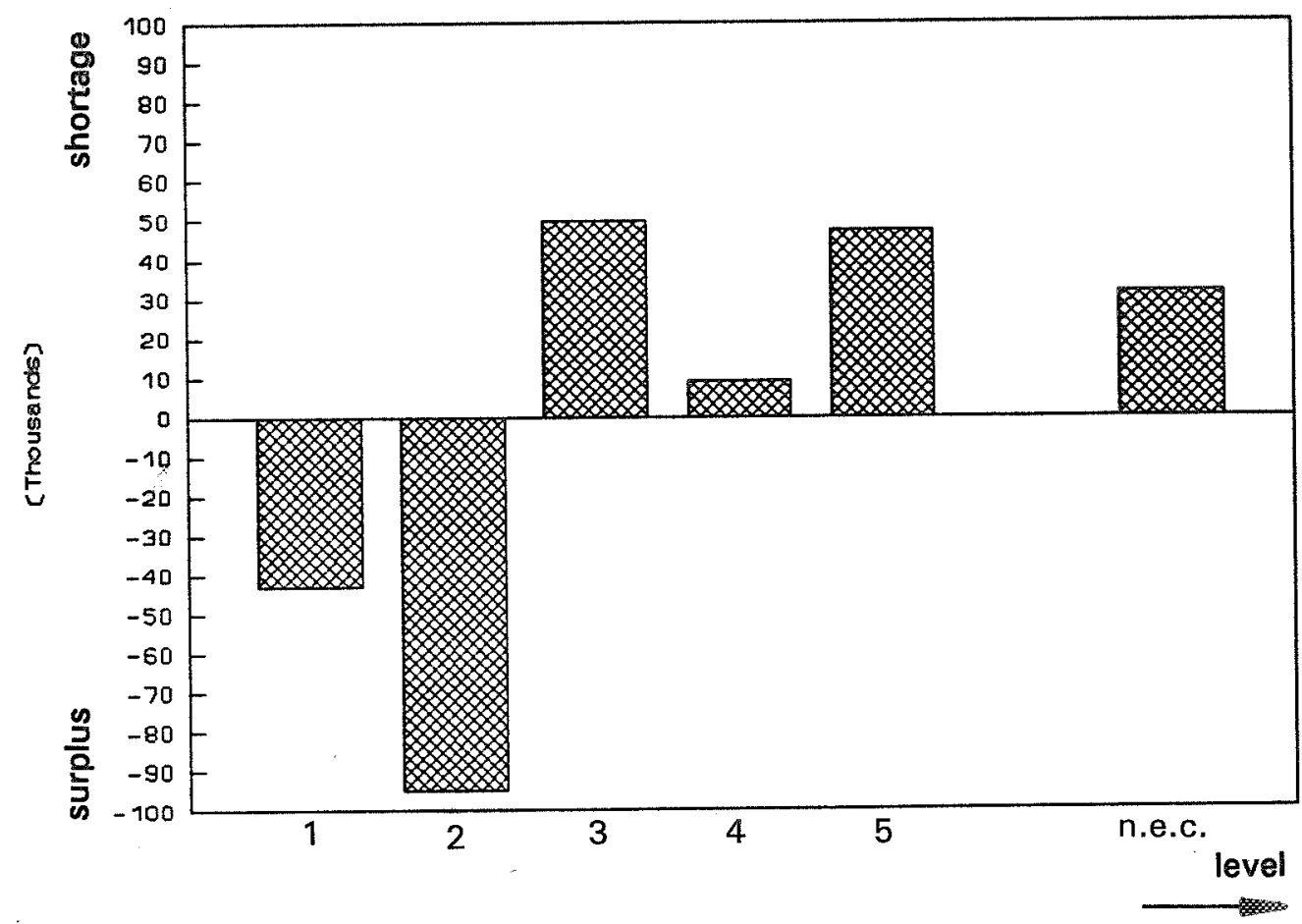




\section{CONCLUSIONS}

In this paper the manpower requirement approach for forecasting the educational structure of occupations has been considered, and an attempt has been made to investigate both the theoretical and empirical problems this approach is confronted with. Furthermore, a model has been developed to overcome these problems.

From a theoretical point of view it has been argued that a shortcoming of the manpower requirement model is that it does not explicitly state the meaning of the 'requirements' which play a crucial role in the model. Therefore, the model gives neither answer to the question how gaps between requirements and supply of labour can be recognised in the data, nor the question in what form future gaps will be realised. This leads to an inconsistent approach in the econometric implementation of the models. Since mostly in the past realised demand is used as a measurement of the requirement, which by definition is equal to supply, while in the forecast requirements and supply might converge.

A second theoretical shortcoming is the absence of substitution. Since the model does not explicitly incorporate the consequences of surpluses and shortages, it also does not include the substitution possibilities, between closely connected educations.

Empirically, it has been shownin this paper that the manpower requirement models might provide forecasts which do not improve (or even are worse than) a simple Same As Before (SAB) model.

The only model in literature which overcomes these shortcomings is the RAS model. The structure of the RAS model, however, makes it difficult to extend this mechanical model with economic variables. Furthermore, the RAS model provides no figures about the supply-demand gaps. Therefore an alternative to the RAS model is developed in this paper.

It is shown that RAS and the manpower model developed in the paper have a forecast quality which is much better than the usual manpower requirement models. Also three extensions of the manpower model a presented. Although these models provide estimates which give an interesting description of the developments of the labour market, the improvements of the forecast qualities are only marginal. A possible reason for this is that while the main interest of the model is in the gap between supply and demand, the estimation is focussed on improving the forecast of the actual employment on the labour market. By using education methods like developed in Wieling and Borghans (1994) in which the consequences of the gaps for the labour market position of schoolleavers are considered, the usefullness of the manpower models with substitution could be further improved. 


\section{REFERENCES}

Berendsen, H., R.J.P. Dekker, A. De Grip, and P.J.E. van de Loo (1992), 'Prognose arbeidsmarktinstroom van schoolverlaters per opleidingstype'. ROA-W-1992/1, Maastricht.

Berendsen, H., A. de Grip, and E.J.T.A. Willems (1991), 'Gevraagd Bèta-onderzoekers (I)'. Economisch Statistische Berichten 76, pp. 652-654.

Blaug, M. (1972), An Introduction to the Economics of Education. Middlesex.

Blien, U., and M. Tessaring (1992), 'Transition Between Education and the Labour Market in Germany. The Application of the ENTROP Procedure in the Educational Accounting System'. Paper presented at the EALE Annual Conference, Warwick.

Borghans, L. (1993), Educational Choice and Labour Market Information. Ph.D.Thesis, Maastricht.

Bosworth, D.L., Evans, G.J., and R.M. Lindley (1974), 'Mechanistic Manpower Models'. In Wabe (Ed.), Problems in Manpower Forecasting, pp. 61-84.

CBS (1982), Arbeidskrachtentelling 1979; deel 1 methode, bevolking en beroepsbevolking, werkzame personen en werklozen. Den Haag.

CBS (1985), Arbeidskrachtentelling 1981; deel 1 methode, bevolking en beroepsbevolking, werkzame personen en werklozen. Den Haag.

CBS (1986), Arbeidskrachtentelling 1983. Den Haag.

CBS (1987), Arbeidskrachtentelling 1985. Den Haag.

Dekker, R.J.P., and A. de Grip (1992), 'Vergelijking tussen CBS- en de ROAberoepenclassificatie'. ROA-W-1992/3, Maastricht.

Dekker, R.J.P., A. de Grip, H. Berendsen, M.H. Wieling, and E.J.T.A. Willems (1992), 'Methodiek en structuur arbeidsmarktmodule I-See!'. ROA-W-1992/1, Maastricht.

Dekker, R.J.P., A. de Grip, and P.J.E. van de Loo (1990), 'ROA-Beroepenclassificatie 1990'. ROA-W-1990/9, Maastricht.

De Grip, A. and J.A.M. Heijke (1988), 'Labour Market Indicators: An Inventory'. ROA-W1988/1E, Maastricht.

De Grip, A., L.F.M. Groot, and J.A.M. Heijke (1991), 'Defining Occupational Groupings by Educational Structure'. Environment and Planning A, pp. 59-85.

Evans, G.J., and R. Lindley (1973), 'The Use of RAS and Related Models in Manpower Forecasting'. Economics of Planning 13, pp. 53-73.

Evans, G.J., and J.S. Wabe (1974), 'Testing a Demand Explanation of the RAS Model'. In Wabe (Ed.), Problems in Manpower Forecasting, pp. 85-95. 
Heijke, H. (ed.), Foreasting the Labour Market by Occupation and Education. Boston.

Judge, G.G., W.E. Griffiths, R.C. Hill, and J.-C. Lee (1980), The Theory and Practice of Econometrics. New York.

Kadas, S.A., and E. Klafszky (1976), 'Estimation of the Parameters in the Gravity Model for Trip Distribution: a New Model and Solution Algorithm'. Regional Science and Urban Economics 6, p. 439.

Peeters, H.M.M. (1990), 'An Explanation of the Occupational and Educational Structure of Employment by Means of Multinominal Logit'. ROA-W-1990/4E, Maastricht.

Soumelis, C. (1983), 'An Overview'. In OECD, Educational Planning: A Reappraisal, pp. 12-51.

Theil, H. (1967), Economics and Information Theory. Amsterdam.

Van Eijs, P. (1993), 'The Manpower Requirement Approach: Background and Methodology'. ROA-RM-1993/5E, Maastricht.

Van Eijs, P., and L. Borghans (1993), 'Manpower Forecasting and the Aggregation Problem: A Microeconomic Approach'. ROA-RM-1993/6E, Maastricht.

Van Eijs, P. (1994), 'Manpower Forecasting in the Western World: The Current State of the Art'.ROA-RM-1994/1E, Maastricht.

Wieling, M. and L. Borghans (1994), 'Discrepancies between Demand and Supply and Adjustment Processes on the Labour Market'. ROA-RM, forthcoming, Maastricht.

Willems, E.J.T.A., and A. de Grip (1993), 'Forecasting Replacement Demand by Occupation and Education'. International Journal of Forecasting 9, pp. 173-185. 


\section{APPENDIX 1. OCCUPATIONS WITH THEIR OCCUPATIONAL LEVEL IN 1985}

level

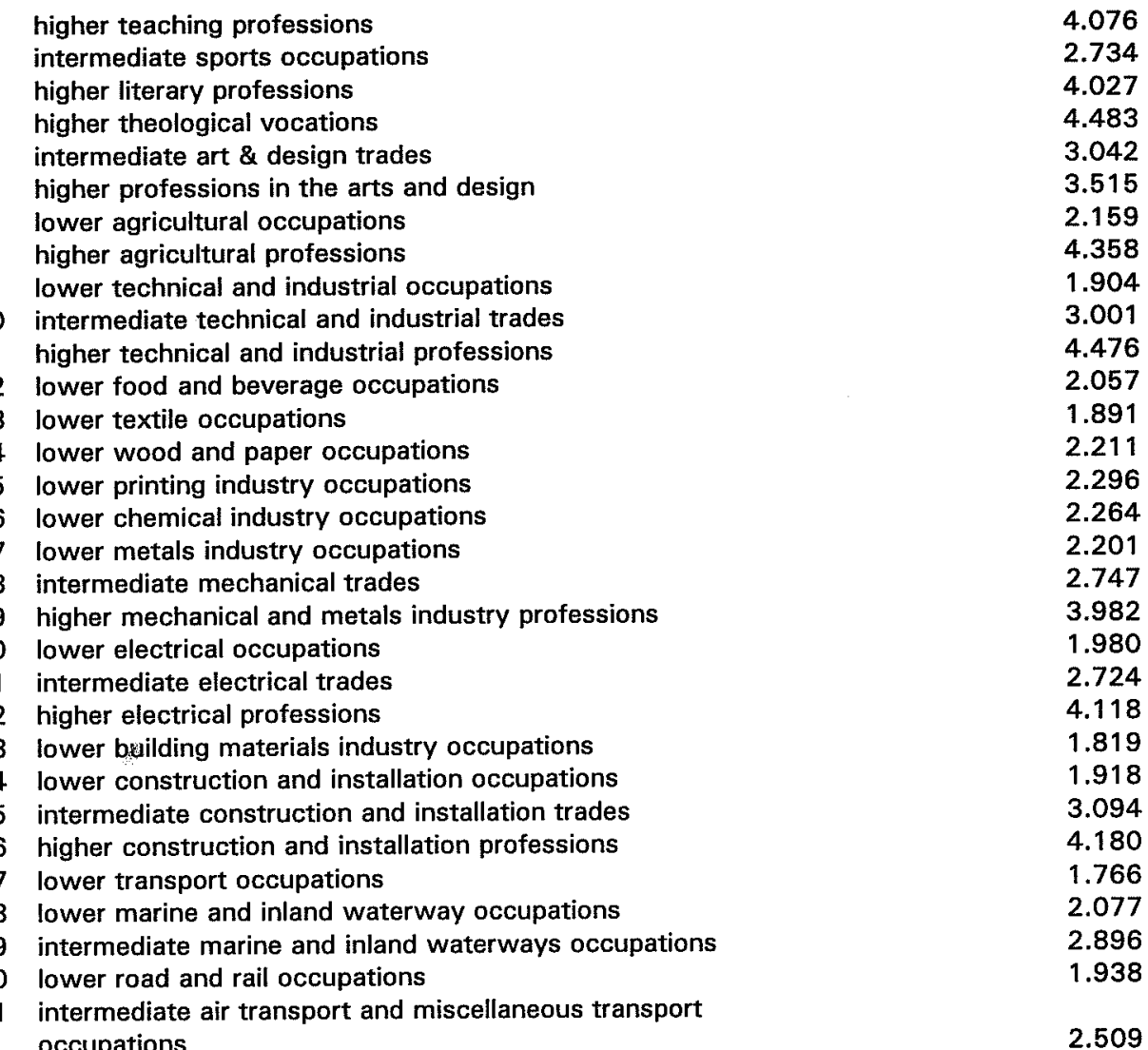

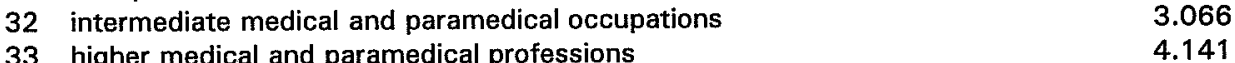

34 higher commercial and administrative professions 3.613

35 lower administrative occupations $\quad 2.130$

36 intermediate administrative occupations $\quad 2.720$

37 higher administrative professions $\quad 3.715$

38 lower sales and purchasing occupations $\quad 2.227$

39 intermediate sales and purchasing occupations $\quad 2.754$

40 higher legal and government professions $\quad 4.256$

41 intermediate socio-cultural occupations $\quad 3.457$

42 higher socio-cultural professions $\quad 4.005$

43 lower hotel and catering occupations $\quad 2.015$

44 intermediate hotel and catering occupations $\quad 2.484$

45 lower service occupations 2.014

46 intermediate service occupations $\quad 2.848$

47 intermediate police, fire, and security occupations $\quad 2.723$

48 intermediate military occupations $\quad 2.786$

49 occupations n.e.c. $\quad 2.747$ 


\section{APPENDIX 2. TYPES OF EDUCATION WITH THEIR INSTITUTIONAL LEVEL IN 1985}

institutional

level

1 Primary Education

2 Lower General Secondary Education

Lower Vocational Education, Agriculture

Lower Vocational Education, Technical

Lower Vocational Education, Transport \& Harbour

Lower Vocational Education, Commerce \& Administration

Lower Vocational Education, Community Care, Hotel \& Catering

Lower Vocational Education, Security

Lower Vocational Education, n.e.c

Higher General Secondary Education

1 Intermediate Vocational Education, Agriculture

12 Intermediate Vocational Education, Non-Medical laboratory

3 Intermediate Vocational Education, Engineering

14 Intermediate Vocational Education, Transport \& Harbour

15 Intermediate Vocational Education, Medical Laboratory

16 Intermediate Vocational Education, Nursing \& Para-medical services

17 Intermediate Vocational Education, Commerce \& Administration

18 Intermediate Vocational Education, Administrative, legal \& Fiscal

19 Intermediate Vocational Education, Social \& Cultural

20 Intermediate Vocational Education, Community Care

21 Intermediate Vocational Education, Hotel, Catering \& Hairdressing

22 Intermediate Vocational Education, Police, Fire \& Defense Forces

23 Intermediate Vocational Education, n.e.c

24 Higher Vocational Education, Teacher Training

25 Higher Vocational Education, Interpreter \& Translator

26 Higher Vocational Education, Theology

27 Higher Vocational Education, Agriculture

28 Higher Vocational Education, non-medical Laboratory

29 Higher Vocational Education, Engineering

30 Higher Transport \& Harbour

31 Higher Vocational Education, Medical Laboratory

32 Higher Vocational Education, Nursing \& Physiotherapy etc

33 Higher Vocational Education, Commerce \& Administration

34 Higher Vocational Education, Business Administration Technology

35 Higher Vocational Education, Administrative, Legal \& Fiscal

36 Higher Vocational Education, Social \& Cultural

37 Higher Vocational Education, Hotel \& Catering Industry

38 Higher Vocational Education, Fine Arts

39 Higher Vocational Education, Police, Fire \& Defense Forces

40 Higher Vocational Education, n.e.c

41 Academic Education, Teacher Training

42 Academic Education, Arts

43 Academic Education, Theology

44 Academic Education, Agriculture

45 Academic Education, Mathematics \& Natural Sciences

46 Academic Education, Engineering

47 Academic Education, Veterinary \& Medical Sciences \& Dentistry

48 Academic Education, Pharmacy

49 Academic Education, Economics, Econometrics \& Business Administration

50 Academic Education, Law \& Public Administration

51 Academic Education, Social Sciences

52 Academic Education, Fine Arts

53 Academic Education, n.e.c

54 Education, n.e.c 


\section{APPENDIX 3. THE INCORPORATION OF UNEMPLOYMENT IN THE MANPOWER MODEL (7.9)-(7.13)}

In the manpower model in section 7 the possibility of unemployment has not been taken into account. The data used for the empirical investigations does not allow the introduction of unemployed, but of course this abstraction is very unrealistic and unsatisfactory. Therefore, in this appendix the possibilities of incorporating unemployment in the model a described.

A straightforward approach to get unemployment in the model is by regarding the unemployed as an additional occupational class. The theoretical model in that case is unchanged. This practical approach has, however, two disadvantages. Firstly, the people who are already unemployed in $t-1$ will not be regarded as additional supply in $t$. Therefore, in case of a high structural level of unemployment the gap figures will underestimate the problems at the market. Secondly, if people become unemployed, according to (46) they will substitute other unemployed, in order to satisfy the aggregate equalities.

To overcome these problems it is therefore better to adjust the model for the existence of unemployment. Figure 11 illustrates a possible extension. Together with the usual supply also the unemployed will search a job at the market. To incorporate the lower effectiveness of this group they can be added partly to the used group of suppliers. Due to the possibility of unemployment the sum $\sum \alpha_{i j}$ might be higher than -1 . The additional group $g_{1}\left(1+\sum \alpha_{i j}\right)$ becomes unemployed. Since the sums of the demand in each occupation-education-combiriation equals the aggregate figures, this aggregate equality will also hold for the rest group of unemployed.

Figure 7. The manpower model with substitution including unemployment

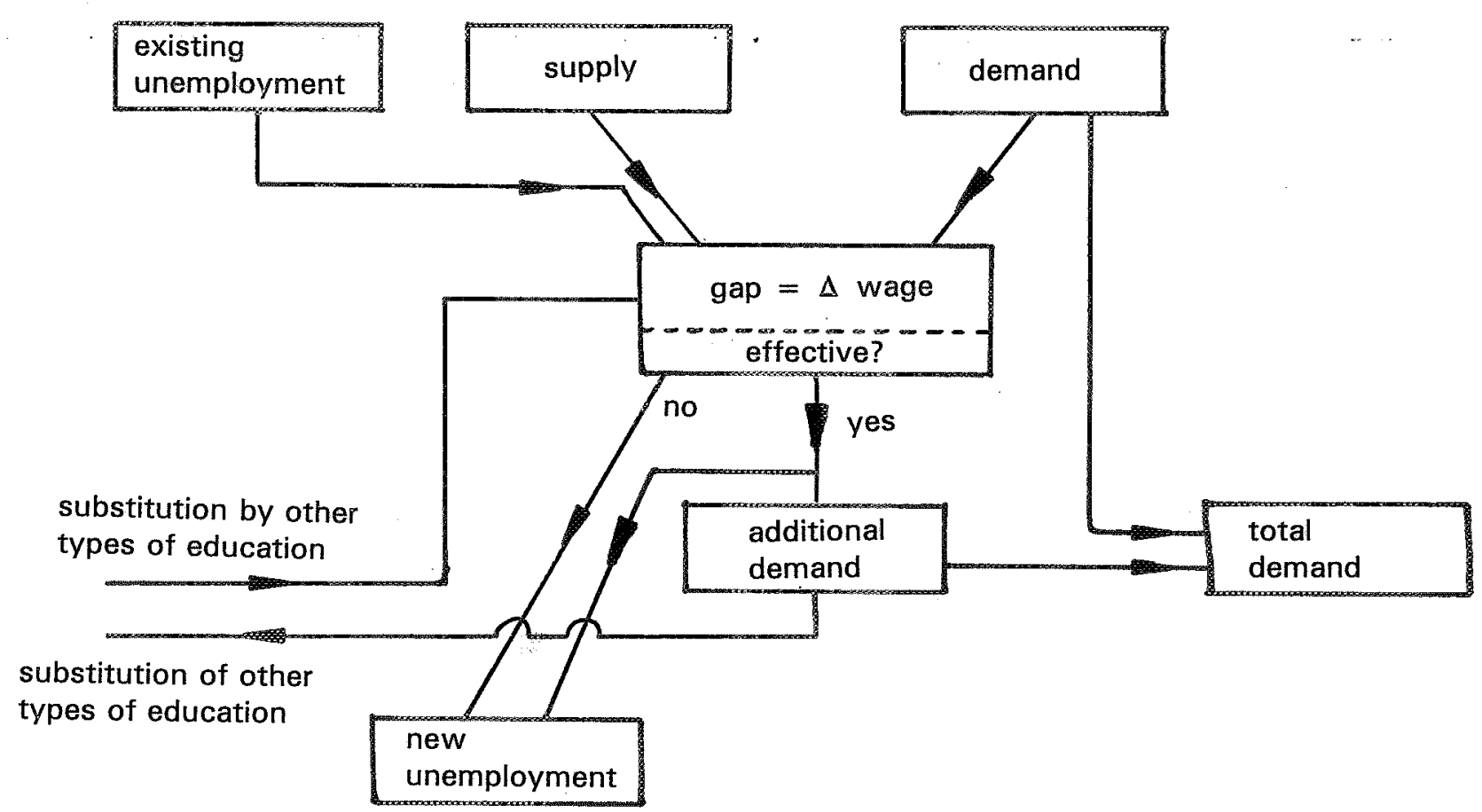

